\title{
1 Oxytocin facilitates communicative adjustment by upregulating \\ broadband aperiodic neural activity
}

3

4

5

6

7

8

9

10

11

12

13

14

15

16

17

18

19 Corresponding author:

20 R. Liu (ruiliu.psy@gmail.com) or I. Toni (ivan.toni@donders.ru.nl)

21 Donders Institute for Brain, Cognition and Behaviour, Radboud University, Kapittelweg 29,

226525 EN Nijmegen, The Netherlands.

1. Donders Institute, Radboud University, Nijmegen, The Netherlands. 2. Psychological and Brain Sciences, Dartmouth College, Hanover, NH, USA.
Rui Liu ${ }^{1,}$, , Arjen Stolk ${ }^{1,2}$, Miriam de Boer ${ }^{1}$, Robert Oostenveld ${ }^{1}$, Ivan Toni1 ${ }^{1,}$ 


\section{Abstract}

2 Oxytocin modulates various social behaviors. In humans, oxytocin has been shown to

3 modulate recipient design, i.e. how communicators adjust to their presumed mutual

4 knowledge. Here, we investigate electrophysiological correlates of the oxytocinergic

5 modulation of recipient design. Fifty-one males were randomly assigned to receive double-

6 blind intranasal administration of oxytocin or placebo. While acquiring

7 magnetoencephalography, the participants engaged in a live communicative task with two

8 different addressees, a child and an adult. Unbeknownst to the participants, a confederate

9 played the role of both addressees, with matched communicative behaviors. All participants

10 started the task by putting more emphasis on their communicative behaviors when they

11 thought to be interacting with the child addressee. As the communication progressed, the

12 oxytocin group reduced variability in their communicative adjustments, adapting more

13 effectively than the placebo group to the matched communicative behavior of the addressees.

14 The magnitude of this oxytocin-related dynamic communicative adjustment was

15 proportional to increased broadband aperiodic power, an index of local synaptic activity, in

16 the right prefrontal-temporal circuit. These findings indicate that oxytocin facilitates

17 dynamic adjustments in recipient design by enhancing cortical signal-to-noise in a portion of the same cortical circuit known to support the production of novel communicative behaviors.

\section{Key words:}

21 recipient design; social interaction; oxytocin; aperiodic neural activity; ventral prefrontal 

cortex 


\section{Introduction}

2 Oxytocin is a pituitary neuromodulator that influences social behaviors by facilitating

3 perception of social cues and by regulating valuation and motivational processes (Bartz et al.,

4 2011; De Dreu, 2012; Gangopadhyay et al., 2021; Grinevich \& Stoop, 2018; Ma et al., 2016;

5 Piva \& Chang, 2018; Shamay-Tsoory \& Abu-Akel, 2016). Recent works have focused on oxytocin's ability to modulate mental state inferences and interpersonal coordination (Arueti et al., 2013; De Coster et al., 2019; Domes et al., 2007; Levy, Goldstein, Zagoory-Sharon, et al., 2016; Levy et al., 2017; Mu et al., 2016; Radke \& de Bruijn, 2015; Spengler et al., 2017; Wu \& $\mathrm{Su}, 2015)$, which led to the suggestion that oxytocin might promote cognitive exploration of a conceptual space (de Boer et al., 2017; De Dreu et al., 2014, 2015; Kapetaniou et al., 2021; Ye et al., 2017). However, it remains unclear how this slow-acting neuromodulatory hormone influences the electrophysiological activities implementing cognitive exploration, as often required to achieve conceptual coordination during human communication. 
modulates human communicative actions, a fundamental dimension of human social cognition largely ignored by previous studies of the oxytocinergic system. We exploit the fact that human communicators adjust their referential signals to the presumed characteristics and knowledge of the addressee of those signals ("recipient design"; Campisi \& Özyürek, 2013; Clark \& Murphy, 1982; Fussell \& Krauss, 1989; Galati \& Brennan, 2010; Levinson, 2006; Newman-Norlund et al., 2009; Tomasello, 2008; Toni \& Stolk, 2019; Yoon \& Brown-Schmidt,

2014). Previous work has shown that oxytocin boosts participants' recipient design, driving them to adjust their communicative behavior to the actual level of understanding experienced in the addressees, and away from their expectations of the addressees' cognitive abilities (de Boer et al., 2017). Following this hypothesis, we report a novel analysis of the dynamics of recipient design adjustment produced by communicators, and investigate the electrophysiological mechanisms supporting oxytocinergic effects on recipient design.

Previous studies have consistently shown the involvement of the temporal and ventral prefrontal cortex in the right hemisphere during the production, comprehension, and adjustment of communicative behaviors while adopting recipient design (Noordzij et al., 2009, 2010; Stolk, Verhagen, et al., 2013; Stolk et al., 2015). Accordingly, we reasoned that, if oxytocin modulates recipient design, then it is likely to happen at the level of the righthemispheric temporo-frontal upregulation of electrophysiological activity evoked by a communicative challenge (Stolk, Verhagen, et al., 2013; Stolk et al., 2015). Furthermore, as shown in a previous MEG study, selecting and understanding communicative actions evoked matched broadband responses (30-250 Hz) in communicators and addressees (Stolk, 
1 Verhagen, et al., 2013). In the last decade, accumulating evidence has pointed out that

2 broadband gamma electrophysiological activity is a mesoscopic correlate of action potentials

3 and dendritic currents in recurrent neural circuits, different in origin and functional

4 characteristics from narrowband oscillations (gamma: 60-80 $\mathrm{Hz}$ ) evoked in superficial

5 cortical layers by feedforward processing of sensory stimuli (Bartoli et al., 2019; Bastos et al.,

6 2018; Buzsaki \& Schomburg, 2015; Chaoul \& Siegel, 2020; Donoghue et al., 2020; Leszczyński

7 et al., 2020; Manning et al., 2009; Miller et al., 2009, 2014; Pettersen et al., 2014; Ray et al.,

8 2008; Ray \& Maunsell, 2011; Thivierge \& Cisek, 2008; Touboul \& Destexhe, 2010; Voytek et

9 al., 2015). Thus, in the current study, we carefully differentiated periodic and aperiodic

10 neural activities and tested their behavioral effects on communicative adjustment modulated

11 by oxytocin administration (Wen \& Liu, 2016).

12 In sum, this study explored electrophysiological mechanisms supporting recipient design

13 adjustments, and the oxytocinergic modulation of those adjustments. After receiving

14 intranasal oxytocin or a placebo, electrophysiological activity was measured with MEG while

15 participants were engaged in live, non-verbal communicative interactions between a

16 communicator (the participant) and two presumed addressees (a confederate) (Tacit

17 Communication Game, Figure 1; de Boer et al., 2017; Newman-Norlund et al., 2009; Stolk et

al., 2015; Stolk, Hunnius, et al., 2013). We predicted that oxytocin regulates recipient design 


\section{Methods}

\section{Participants}

3 Fifty-eight male participants (mean $\pm S D=22 \pm 3$ years), naïve to the experiment task, signed

4 informed consent according to the study protocol approved by the local ethics committee

5 (Committee on Research Involving Human Subjects, Region Arnhem-Nijmegen, the

6 Netherlands; study protocol registration number 37419.091.11). Assuming a medium-large

7 effect size (Cohen's d between .5 and .7) of oxytocin on communicative behavior, a sample

8 size between 26 and 49 in each of the two groups (oxytocin and placebo) was deemed to

9 provide adequate power (80\%) to detect the presence of an effect of the intervention, at a

10 significance level of .05 . The enrolled participants were asked to refrain from caffeine, alcohol

11 and/or cigarettes 24 hours prior to the experiment and from food or drink (except water) 2

12 hours prior to the experiment. Three participants were excluded during behavioral analysis

13 (one participant did not seem to understand the instructions of the task; one participant did not believe our manipulation indexing communicative adjustment, one participant data

15 acquisition failed. see de Boer et al., 2017), and four other participants were excluded in the current report due to lack of neuroimaging data (Two participants had no MRI recording, one

17 participant had no MEG recording and one participant had no head-location recording)

18 (Supplementary 1). 24 participants in the oxytocin group and 27 participants in the placebo group remained in the final analysis. 
2 The participants were randomly assigned to one of the two groups and double-blindly

3 received self-administered intranasal sprays of either 24 IU (three puffs per nostril, each with

44 IU) oxytocin (Syntocinon, Novartis, Basel, Switzerland) or placebo (sodium chloride

$58 \mathrm{mg} / \mathrm{ml}$ and benzalkonium chloride $.1 \mathrm{mg} / \mathrm{ml}$ ). The neuropeptide and saline solution were

6 prepared and stored by the pharmacy of the Radboud University Medical Centre. After 45

7 minutes of the pharmacological administration, the participants sat into the MEG scanner,

8 adjusted themselves to comfortable position, and then practiced for three trials to get

9 familiar with the game-controller and the measuring environment. The MEG scanning

10 preparation and experiment task lasted for about 30 minutes in total. Immediately

11 afterwards, participants answered a questionnaire on the characteristics of the addressees

12 (Newman-Norlund et al., 2009) and a 7-points Likert scale on their beliefs on the substance

13 and dosage of the pharmacological treatment they had received. Furthermore, we verified

14 that the two groups consisted of participants matched along study-relevant dimensions by

15 measuring a number of physiological and psychological indexes (de Boer et al., 2017; Radke

16 et al., 2017, Supplementary 2).

\section{Experimental Task and Design}

18 We used the TCG task to quantify communicative behavior between a communicator (a

19 participant) and an addressee (the confederate) (de Ruiter et al., 2006, 2010; Newman-

20 Norlund et al., 2009; Noordzij et al., 2009, 2010; Stolk, Verhagen, et al., 2013; Stolk, Hunnius, 
et al., 2013; Stolk et al., 2015; de Boer et al., 2017). While sitting in separate rooms, each

2 communicator-addressee pair jointly collected a target object (an acorn) from a location (one

3 of the red-and-white circles) in a Target-Field (one of the nine grids) on a digital game board

4 of 3-by-3 grids (Figure 1). Only the communicator was aware of the target's location, and

5 only the addressee could collect the target. The communicator could move a bird token on

6 the game board with a gamepad, in order to generate moving patterns that could be seen and

7 interpreted by the addressee as signals for the target location. However, the bird token could

8 only move to the center of each of the nine grids, and only through vertical or horizontal

9 displacements (see Figure 1A, “2. MOVEMENT”). Such moving restrictions of the bird token

10 required the communicator and the addressee to disambiguate one among multiple potential

11 target locations within a grid, based on movements of the bird token. The addressee

12 controlled a squirrel token with a computer mouse; and could move freely on the game board

13 and had a direct access to any location when collecting the target (see Figure $1 \mathrm{~B}$, " 4.

14 MOVEMENT"). 
A)

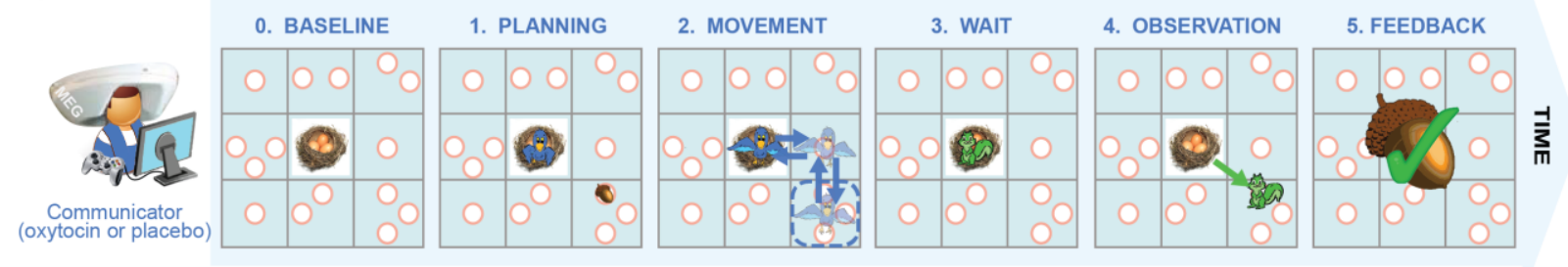

B)
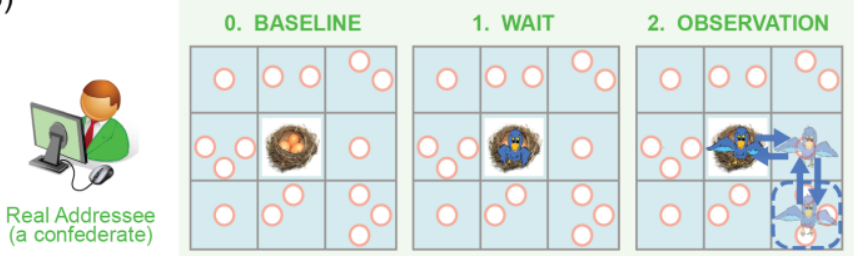

3. PLANNING

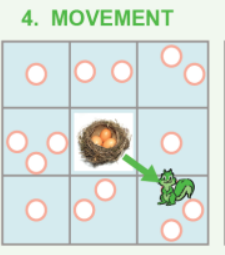

5. FEEDBACK
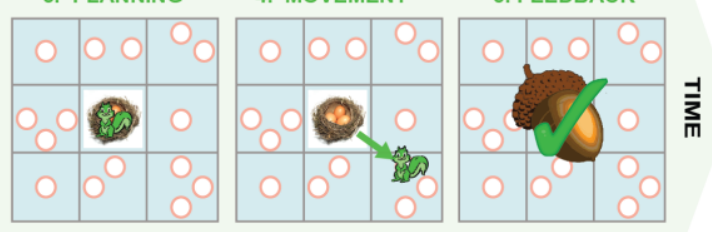

Figure 1. Time-course of a TCG trial. A) Communicator's view. B) Addressee's view. The TCG task required two players to collect targets (acorns) jointly from the nine-grid (fields) game board. Using MEG, we measured neural activity while participants played as communicators (in blue), following administration of either oxytocin or placebo. A confederate sat in a separate room and played the TCG as addressee (in green). Each trial is consisted of six successive epochs illustrated with the time line of the figure. The trial starts with a blank game board visible to both players (3 secs, 0. BASELINE). Afterward, a bird appears on both player's screens, whereas the acorn is only visible on the communicator's screen. Meanwhile, the communicator plans how to solve the trial (A1. PLANNING). To this end, the communicator needs to indicate to the addressee the location of the acorn on the game board, and that can only be achieved by moving the bird. Namely, only the communicator can move the bird, vertically and horizontally, from the center of one field to the center of another adjacent field (A2. MOVEMENT). The bird cannot be overlaid on the red circle containing the acorn. Therefore, in those fields with multiple potential acorns' locations (red-and-white circles), the communicator needs to generate a moving pattern of the bird that is visible and understood by the addressee to disambiguate the relevant circle. In the example above, the communicator signals the relevant field to the addressee by holding the bird there for longer (Time on Target-Field) than the time spent on other fields of the board. Furthermore, the communicator would try to mark the relevant circle, e.g. by entering and exiting the field with the acorn from above, intersecting the relevant circle in the process. In the subsequent epoch, the bird disappeared and a squirrel become visible to both players, the communicator waits for the addressee's response (A3. WAIT). Only the addressee can move the squirrel, anywhere on the game board. After interpreting the referential motion pattern of the bird made by the communicator, the addressee indicates the inferred location of the acorn by moving the squirrel onto a circle. The communicator can see the movement of squirrel (A4. OBSERVATION). The trial ends with a feedback shown to both players (5. FEEDBACK). 
2 Previous works have shown that, in this experimental setup, communicators spontaneously

3 generate communicatively specific adjustments towards younger presumed addressees, in

$4 \quad$ line with similar observations obtained during language use (Brand et al., 2002; Brodsky \&

5 Edelman, n.d.; Grieser \& Kuhl, 1988; Newman-Norlund et al., 2009; O’Neill et al., 2005; Stolk

6 et al., 2015; Stolk, Hunnius, et al., 2013; Warren-Leubecker \& Bohannon, 1984). Building on

7 those observations, we informed the participants that they would complete the TCG task with

8 two addressees, an Adult and a Child, sitting in separate rooms with their own monitors to

9 watch the communicator's token moving on the game board. The task contained 50 trials that

10 were distributed into five Adult blocks and five Child blocks. Each block consisted of five

11 consecutive trials in which the communicator interacted with the same presumed addressee

12 (either Adult or Child). In reality, one confederate performed as addressee without knowing

13 the roles of Adult and Child, resulting in statistically matched addressee's performance

14 between Adult and Child (Supplementary 2). Therefore, the two types of blocks differed only

15 in terms of the communicator's expectations about the presumed addressees' abilities to

16 interpret the referential signals. Each participant randomly started with either an Adult or a

17 Child block, and then alternatively switched between the two types of blocks. Each

18 participant was informed about the addressee identity by a picture of adult or child, which

19 was displayed at the center of the screen for 5 seconds at the beginning of each block and in

20 the top-right of the screen throughout the block of five trials (Figure 2A). 
A)

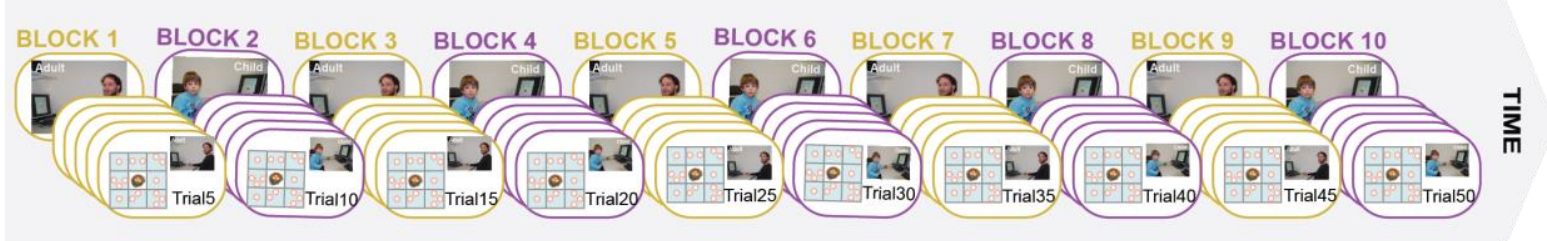

B)

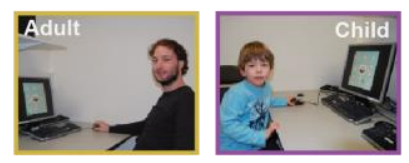

Presumed Addressees (Adult or Child)

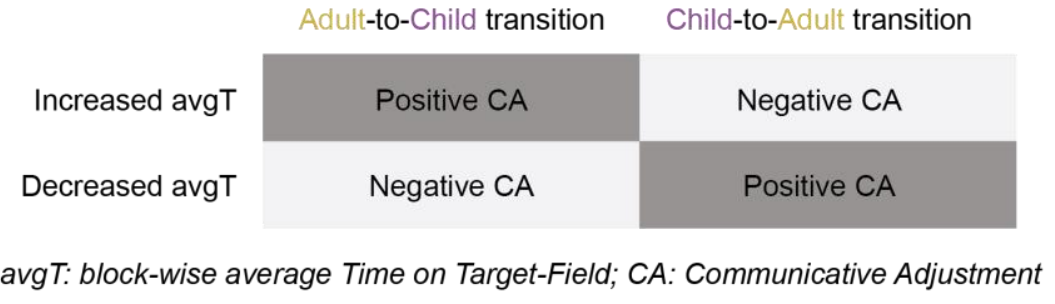

Adult-to-Child transition Child-to-Adult transition

Figure 2. Time-course of the experiment and quantification of communicative adjustment. A) Each communicator (participant) plays 50 trials, organized in ten blocks of five trials. A child and an adult alternated as presumed addressees between each block. In each block, the communicator (the participant) is informed about the identity of the presumed addressee by means of a photo shown at the beginning of each block and next to the game board throughout the trials. Unbeknownst to the communicator, a confederate played both presumed addressees without knowing the presumed addressee's identity. B) This experimental setup quantifies recipient design, with communicators spending longer time on the field containing the acorn (Time on Target-Field, see Figure 1) when they believe to be playing with the child than with the adult presumed addressee, despite matched performance of the confederate playing those two roles. We quantify recipient design with a dynamic index, Communicative Adjustment (CA), namely, a block-by-block Time on TargetField difference, positive when the average Time on Target-Field towards a child addressee was longer than the corresponding average in the preceding block with an adult addressee and negative when the average Time on Target-Field decreased during Adult-to-Child block transitions. The inverse block transitions (Child-to-Adult) were indexed with an inverse CA sign.

\section{Indexing Dynamics of Communicative Adjustment}

This experiment builds on several studies showing that the time spent by communicators on a communicatively relevant referent provides a quantitative index of recipient design, in both laboratory and naturalistic contexts (Sacks et al., 1978; Newman-Norlund et al., 2009, 2009; 
1 Noordzij et al., 2009, 2010; Stolk, Hunnius, et al., 2013; Stolk, Verhagen, et al., 2013; Stolk et

2 al., 2015; de Boer et al., 2017; Murillo Oosterwijk et al., 2017; Liu et al., 2019). Following

3 previous studies using this experimental setup, we labeled the time spent by communicators

4 on the relevant referent as Time on Target-Field, i.e. the time interval between the bird token

5 entering and leaving the Target-Field (Newman-Norlund et al., 2009; Stolk, Hunnius, et al.,

6 2013; Stolk, Verhagen, et al., 2013; Stolk et al., 2015; de Boer et al., 2017). In case the Target-

7 Field was visited multiple times within a trial, then we conservatively averaged the intervals

8 on Target-Field (Figure 1A, "2. MOVEMENT"). In a previous analysis of the same behavioral

9 data considered here, De Boer et al. (2017) quantified recipient design as the difference between the time communicators spent on Target-Field when interacting with a presumed

Adult or Child addressee. In that study, it was shown that, in contrast to the placebo group, participants receiving oxytocin did not differentiate between the two presumed Addressees (as indexed by the Time on Target-Field averaged across trials). Here, differently from the previous analysis, we focused on new indices of recipient design that capture the dynamics of communicative adjustment towards the two presumed addressees. We considered a previously ignored feature of the experimental design, namely the difference between the with different presumed addressees (Figure 2A). Building on the a priori knowledge that communicators spend longer Time on Target-Field when believing they are interacting with a presumed Child addressee than an Adult addressee, we considered a lengthened Time on Target-Field for a Child-addressee block compared to the previous Adult-addressee block as 
1 positive communicative adjustment, and a shortened Time on Target-field for a Child-

2 addressee block compared to the previous Adult-addressee block as negative communicative

3 adjustment (Figure 2B). Formally, we defined Communicative Adjustment [CA(t); eq. 1] as

4 the absolute local difference of averaged Time on Target-Field (avgT) between two successive

5 blocks (block $\mathrm{k}_{\mathrm{t}+1}$ and blockt) multiplied by a step function $\mathrm{D}(\mathrm{t})$ indicating the direction of

6 addressee transitions ( " +1 " for Adult-to-Child transitions and "- 1 " for Child-to-Adult

7 transitions).

8

9

$$
C A(t)=|\operatorname{avg} T(t+1)-\operatorname{avg} T(t)| \times D(t)
$$

$$
\text { where, }\left\{t \mid t \leq 9, t \in Z^{+}\right\} \text {and } D(t)= \begin{cases}+1 & \text { if transitioning from Adult to Child } \\ -1 & \text { if transitioning from Child to Adult }\end{cases}
$$

We reasoned that the sensitivity of CA(t) to local differences in Time on Target-Field makes CA(t) potentially sensitive to other factors changing differently across blocks but not directly related to recipient design, e.g. procedural learning effects in producing movements of the bird token. We considered planning time as a conservative index of the block-by-block changes in behavior due to procedural learning effects, conservative because planning time might also be influenced by recipient design and communicative difficulty effects. Therefore, the Time on Target-Field data used in computing $\mathrm{CA}(\mathrm{t})$ were residualized against the time spent planning the motor response in the corresponding trials.

The overall statistical model used to quantify influences of oxytocin on recipient design as indexed by $\mathrm{CA}(\mathrm{t})$ was a 2 (Treatment: Oxytocin or Placebo) * 9 (block-wise Addressees Transition within each participant) mixed factorial design. Furthermore, we implemented a 
number of control analyses. First, we tested whether the average CA(t) across block transitions confirmed the findings obtained in de Boer et al., 2017, assessing the presence of a recipient design effect in the placebo group but not in the oxytocin group with an independent-samples t-test. Second, we tested whether the two experimental groups had similar communicative adjustments at the onset of the experiment, i.e. whether the CA(t) measured in the first block of the experiment showed the presence of a positive recipient design effect in both placebo and oxytocin groups, using an independent-samples t-test. Third, we tested whether CA(t) between blocks variability changed in the course of the experiment differently for the oxytocin and the placebo groups. This hypothesis was assessed by considering the within-subject $\mathrm{CA}(\mathrm{t})$ standard deviation during the first- and second-half

11 of the experiment ( $1^{\text {st }}$ to $4^{\text {th }}$ and $6^{\text {th }}$ to $9^{\text {th }}$ block transitions), in a 2 (Treatment: oxytocin, placebo) $\times 2$ (Time: first-half, second-half) mixed-factorial ANOVA. The statistical inferences were conducted with stats, a build-in package of $R$ (Bolar, 2019; R Core Team, 2009). Besides the half-split within-subject variance of $\mathrm{CA}(\mathrm{t})$, we also quantified point-by-point changing rate of CA(t) time course (see Supplementary 5 for further analyses and results). Following a previous study (Stolk et al., 2015), we formulated the post-error communicative adjustment

17 as the difference of Time on Target-field between the trial after an unsuccessful communication and the preceding trial, normalized by the sum of Time on Target-field of the 
2 Participants' electrical brain activity during task performance was recorded with a whole-

3 head CTF system with 275 axial gradiometers (VSM Med Tech, $1200 \mathrm{~Hz}$ sampling rate, 300

4 Hz low-pass filter). The communicator's head position relative to the MEG sensor array was

5 continuously monitored using localization coils attached to the anatomical landmarks, i.e.,

6 the nasion and left and right ear canals (Stolk, Todorovic, et al., 2013). High-resolution T1-

7 weighted images were obtained with a single-shot MPRAGE sequence with a Siemens Avanto

$81.5 \mathrm{~T}$ scanner (176 sagittal slices, $\mathrm{TR}=1730 \mathrm{msec}, \mathrm{TE}=2.95 \mathrm{msec}$, flip angle $=7^{\circ}$, voxel size

$9=1 \times 1 \times 1 \mathrm{~mm}^{3}, \mathrm{FOV}=256 \times 256 \mathrm{~mm}^{2}$ ). During anatomical scanning, the communicator wore a pair of vitamin-E ear capsules at the same locations of the MEG fiducial coils, allowing for coregistration of MRI images and MEG sensors for source reconstruction.

\section{MEG data analysis}

13 The MEG data were analyzed using the FieldTrip toolbox (Oostenveld et al., 2010) with customized MATLAB R2016b (MathWorks, Natick, MA, USA) analysis scripts.

15 Preprocessing. The raw MEG data were high-pass filtered ( $>1 \mathrm{~Hz}$ ) to remove low-frequency noise and segmented into trials, from 2 secs before presentation of the target stimuli until

17 disappearance of the feedback stimuli (To avoid potential residual effect from the previous trial, we did not consider the first second at the beginning of each trial. Figure 1A). Each trial was demeaned to the time window of 0.2 secs right before stimulus-onset for controlling the

20 leakage of non-zero DC component. A Discrete Fourier Transform (DFT) filter was applied to 
minimize $50 \mathrm{~Hz}$ line-noise and its harmonics of 100, 150, 200 and $250 \mathrm{~Hz}$.

2 Source reconstruction and aperiodic spectral analysis. For each participant, we estimated

3 aperiodic source power by combining a Partial Canonical Correlation adaptive beamformer

4 (PCC, Gross et al., 2001; Schoffelen et al., 2008) and Irregular Resampling Auto-Spectral

5 Analysis (IRASA, Wen \& Liu, 2016). There were three major steps. First, we computed normalized lead field matrices with participant-specific volume conductors and source

7 models (Schoffelen et al., 2008). More precisely, the individual anatomical MRIs were coregistered to the CTF coordinates system and then segmented (with $5 \mathrm{~mm}$ smoothing and 0.5 threshold) for constructing volume conductors using a single-shell model of the brain surface (Nolte, 2003). The source model was constructed by linearly transforming a 3D template grid (with $10 \mathrm{~mm}$ resolution, leading to 2982 dipole locations inside the brain compartment) in MNI coordinates into the participant-specific coordinates based on the individual MRIs. The inverse of the transformation positioned the grid points across participants at identical locations in normalized MNI space. Second, we reconstructed time series of interest at each source dipole position. To this end, we first segmented the preprocessed trials of data into $500 \mathrm{msec}$ time series, and then computed the Cross-Spectral series between 0 and $300 \mathrm{~Hz}$. With the balanced length of time series between the two treatment groups, we computed spatial filters at each grid dipole location inside the brain

20 (as well as one location for each eye and one location in between, Supplementary 3) for each 21 frequency independently. The Fourier transformed MEG data at each location were then 
passed through the corresponding spatial filter. The products were then projected onto the

2 dipole direction of maximal power, given the singular value decomposition (SVD) to the real

3 part of the CSD. In order to increase sensitivity towards state-related effects known to be

4 evoked by the communicative demands of the TCG task in temporal-prefrontal circuits (Stolk,

5 Verhagen, et al., 2013), we focus the analysis on the epoch from 2 secs before stimulus

6 presentation until the onset of the communicator response (Figure 1A). Thus, we

7 reconstructed the source-level time series of these epochs by inversely transforming the real

8 part of the estimated maximal dipole moment back to the time-domain. Third, we use IRASA

9 to differentiate aperiodic from periodic components in the reconstructed signals. This

method resamples the MEG signal in time, such that periodic components are symmetrically

redistributed beside its original location in the power spectra after Fourier transformation.

IRASA takes the median of the resample pairs as an estimate of the aperiodic component. We

avoided effects of large amplitude low-frequency signals on IRASA performance (Donoghue et al., 2020) by focusing on the $30-150 \mathrm{~Hz}$ frequency range (Bartoli et al., 2019; Manning et

al., 2009; Ray et al., 2008; Ray \& Maunsell, 2011), previously shown to be involved in

interpersonal referential communication (Stolk, Verhagen, et al., 2013).

17

Statistical inference on MEG effects of oxytocin intervention. We implemented three nested

analyses. First, we implemented a whole-brain analysis over 30-150 Hz averaged aperiodic

source power, contrasting the oxytocin and placebo groups at each dipole location parametric cluster-based permutation tests with cluster-forming threshold $\alpha=.05$, two- 
tailed and 1000 Monte Carlo runs (Maris \& Oostenveld, 2007). Effects of intra-subject variance of head translations and rotations, as well as effects of head size, were removed from the data through a multiple regression analysis considering four principle components that explained more than $98 \%$ variance in those confounds. We verified oxytocinergic effect on averaged broadband aperiodic power at the two local maxima identified in the first analysis, located in the anterior temporal cortex and in the ventral prefrontal cortex, after removing further potential confounds of eye-movements by regressing out estimates of those movements (Supplementary 3). Second, at each local maximum, we tested whether the oxytocin-related effect identified in the first analysis was a manifestation of broadband or band-limited increases in aperiodic power. Accordingly, we contrasted between-group differences in aperiodic activity over 103 frequency bins over the 30-150 Hz range through one-tailed independent-samples t tests $\alpha=.05$ uncorrected for multi-comparisons to privilege sensitivity in this particular analysis). Third, we explored the task-related dynamics of the broadband oxytocin-related effect identified in the first analysis. At each local maximum as mentioned above, we extracted aperiodic power (averaged over the 30-150 Hz) for each experimental block in each participant, contrasting the effects between the oxytocin and placebo groups.

Statistical inference on brain-behavior relations. We examined whether, in the ventral prefrontal cluster showing a main effect of oxytocin intervention, the averaged broadband aperiodic power was related to the degree of Communicative Adjustment (CA) across participants. We used a linear mixed-effects model, with three fixed effects: the 
1 pharmacological treatment (Treatment: Oxytocin or Placebo), aperiodic power averaged

2 over $30 \sim 150 \mathrm{~Hz}$ (Neural Activity), and the interaction between the two factors. We included

3 Participant as the grouping variable and considered three random effects: the random

4 intercept of Participant, the random slope of Transitions (i.e. the block-wise Addressees

5 Transition within each participant, see Indexing Dynamics of Communicative Adjustment),

6 and their interaction; and potential confounding factors (PCs, see eq. 2).

$7 \quad C A \sim$ Neural Activity $*$ Treatment $+(1+$ Transition $\mid$ Participant $)+P C s \quad$ (eq. 2)

8 To verify the spatial and spectral specificity of the brain-behavior correlation identified in

9 the ventral prefrontal cortex, we implemented post-hoc control analyses over rhythmic

10 power from control regions in middle occipital cortex (8-12 Hz, Jensen \& Mazaheri, 2010;

11 Klimesch, 2012; Zhigalov \& Jensen, 2020), posterior parietal cortex (8-12 Hz and 15-25 Hz,

12 Brinkman et al., 2014; Haegens et al., 2011; Stolk et al., 2019), and ventral prefrontal cortex

13 (30-60 Hz, Bartoli et al., 2019; Manning et al., 2009; Ray et al., 2008; Ray \& Maunsell, 2011)

14 (Supplementary 4). The model was fitted with Ime4 (Bates et al., 2015); and the post-hoc

15 comparisons were conducted with emmeans (Lenth et al., 2021). The p-values were

16 computed by t test with Kenward-Roger approximation for denominator degrees of freedom

17 (Halekoh \& Højsgaard, 2014) for degrees of freedom. 


\section{Oxytocin Facilitates Updating of Recipient Design}

2 Here, differently from de Boer et al. (2017), we investigated the temporal dynamics of how

3 communicators adjusted their referential signals towards the presumed different addressees.

4 First, we verified that the novel CA index used in this study, when averaged across addressees' transitions, reproduced one of the main findings reported in (de Boer et al., 2017). Namely, that study found that the placebo group spent longer time than the oxytocin group holding their token on the Target-field when they believed to be communicating with a Child than with an Adult Addressee. Accordingly, we found that communicators who received placebo

9 intranasal sprays revealed a significantly greater CA averaged across all addressee transitions than those who received oxytocin $\left(t_{49}=1.92, p=.031\right.$, Cohen's $d=.54$; Figure 3A).

11 The averaged CA was significantly higher than zero for placebo group (mean $=78 \mathrm{msec}, \mathrm{t}_{26}=$

12 2.21, $\mathrm{p}=.018$, Cohen's $\mathrm{d}=.43$ ), but not for oxytocin group (mean $=-13 \mathrm{msec}, \mathrm{t} 23=-.42, \mathrm{p}$

$13=.661$ ). Second, we verified that, in the first transition between addressee blocks in the experiment, the two experimental groups started the experiment with comparable CA(1) (t $\mathrm{t}_{49}$

$15=.05, \mathrm{p}=.963$, Figure 3B). All communicators showed a positive communicative adjustment

$16\left(\mathrm{CA}(1)\right.$ : mean $=97 \mathrm{msec}, \mathrm{t}_{50}=2.21, \mathrm{p}=.022$, Cohen's $\left.\mathrm{d}=.29\right)$. These results confirm that, at the onset of the experiment, communicators put additional emphasis in their communicative signals when targeting addressees whom they believe to be less cognitively capable. 
1 Supplementary 5 for individual data). In the oxytocin group, CA(t) fluctuated around zero. In

2 the placebo group, there was no clear convergence. Specifically, differently from the placebo

3 group, communicators in the oxytocin group significantly reduced their block-by-block

4 variability in communicative adjustments (Figure 3D; $F_{1,49}=7.38, p=.009, \omega^{2}=.04$ ). More

5 precisely, the standard deviation of $\mathrm{CA}(\mathrm{t})$ in the oxytocin group dropped in the second-half

6 of the experiment ( $\mathrm{t}_{23}=-3.43, \mathrm{p}=.001$, Cohen's $\left.d=.70\right)$, whereas that of the placebo group

7 remained at the same level across first- and second-half $\left(\mathrm{t}_{26}=.20, \mathrm{p}=.578\right)$. These

8 observations indicated that, in contrast to placebo group, the oxytocin group was stabilizing

9 the level of CA(t) over the experiment (see Supplementary 5 for further analyses on changing 10 rate of communicative adjustment).

11
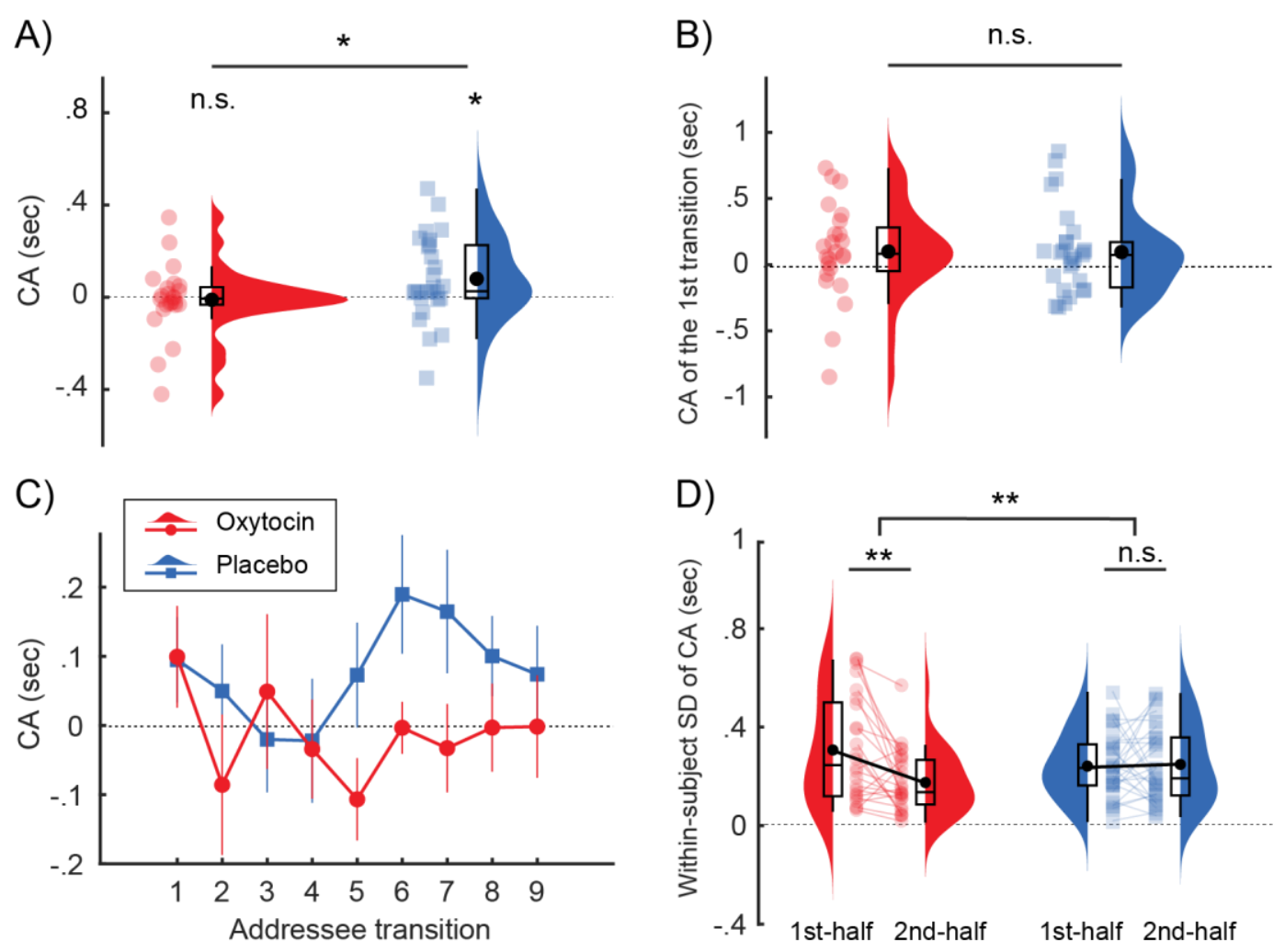
Figure 3. Communicative adjustment behavior. A) Averaged over the whole experiment, the placebo group (in blue) showed a positive Communicative Adjustment (CA), larger than the near-zero CA of the oxytocin group (in red). The curved areas illustrate kernel density estimates of data distribution in each group. Each red dot or blue square is single participant data. The black dots represent the group mean, the black boxes indicate the interquartile range (IQR), and the whiskers are maximum and minimum with 1.5 IQR. B) For the first block transition, the two treatment groups had comparable positive CA values. C) The CA dynamics of the two groups. Filled red dots and blue squares for oxytocin and placebo groups respectively, represent the averaged CAs over each addressee transition. D) The withinsubject variability in CA dynamics differed between the two groups, decreasing in the oxytocin group between the first and the second half of the experiment, but not in the placebo group. Error bars: standard errors of the mean. ${ }^{* *}: \mathrm{p}<.01{ }^{*}$ : $\mathrm{p}<.05$; n.s.: not significant.

Moreover, we verified that the two treatment groups showed matched Time on Target-Field in the first block (Welch's $t_{35}=1.92, p=.06$, Levene's test of variances equality: $F_{1}=5.85, p$ $=.02$ ). Thus, the effects reported above could not be attributed to responding bias or heterogeneity of the initial level of recipient design of the communicators. The effects on the CA(t) could not attributed to the possibility that oxytocin reduced participants' communicative motivation, as oxytocin group revealed a positive post-error communicative adjustment, i.e. lengthen the Time on Target-field after an unsuccessful trial $\left(\mathrm{t}_{23}=2.64, \mathrm{p}\right.$ $=.007$, Cohens' $d=.54)$, which was significantly higher $\left(t_{49}=1.94, p=.029\right.$, Cohens' $\left.d=.54\right)$ than that of the placebo group showing no difference from zero $\left(\mathrm{t}_{26}=.17, \mathrm{p}=.433\right)$. Further control analyses ruled out the possibility that the between-groups differences in CA(t) could be driven by confederate's reaction time, joint error rate, or communicator's total moving time, time on non-target-field and movement steps (Supplementary 2). As reported previously (de Boer 2017), we did not observe any between-group differences in a number of physiological and psychological indexes (e.g. cortisol, testosterone and social traits) or 
beliefs about the psychopharmacological operation (Supplementary 2). Neither did we found evidence that the participants did not believe to be playing with a child and an adult partner (Supplementary 2). Taken together, these observations indicate that, over the course of the experiment, the oxytocin group converged in spending comparable time on the Target-Field for the two addressees and across subsequent blocks of trials. In contrast, the placebo group continued to spend more time on the Target-Field when addressing a child, with substantial between-blocks variability in performance even by the end of the experiment.

Oxytocin tonically upregulates aperiodic broadband power in the right ventral prefrontal cortex

11 Participants receiving oxytocin showed stronger broadband (30-150 Hz) aperiodic power in a right-lateralized cluster spanning ventral prefrontal cortex (vPFC) and anterior temporal

13 (TP), with two corresponding local maxima (Oxytocin > Placebo at vPFC: $\mathrm{t}_{49}=2.41, \mathrm{p}=0.018$; TP: $\left.t_{49}=2.43, \mathrm{p}=.024\right)$; and weaker power than the placebo group in the right posterior related effects on averaged aperiodic power in vPFC $\left(t_{49}=2.22, \mathrm{p}=.021\right)$ and PPC $\left(\mathrm{t}_{49}=-2.13\right.$,

$17 \mathrm{p}=.031$ ), but not $\mathrm{TP}$, persisted after regressing out individual variances of eye-movement noise, head position, and head size. Moreover, the oxytocin-related effects in vPFC and PPC could not be explained by narrowband increases in aperiodic power (extending from 44 to $150 \mathrm{~Hz}$ and from 30 to $150 \mathrm{~Hz}$ respectively, Figure 4B). Exploration of the task-related dynamics of the oxytocin-related vPFC effect indicated a sustained difference between 
1 groups across the ten experimental blocks (minimum $\mathrm{t}_{\mathrm{t}} \mathrm{t}_{49}=1.81, \mathrm{p}=0.043$, Figure $4 \mathrm{~B}$ ), but

not in PPC (minimum t: $t_{49}=-1.54, p=0.077$ ). In sum, these results indicate that exogenous oxytocin induced a tonic upregulation of aperiodic broadband power in ventral prefrontal cortex.

\section{The upregulation of aperiodic broadband power supports oxytocinergic modulation of} recipient design

We asked whether the magnitude of broadband aperiodic power in vPFC was related to the magnitude of communicative adjustment. Besides a main effect of broadband aperiodic power on CA $\left(\mathrm{t}_{403.84}=2.73, \mathrm{p}=.007\right.$, Estimate(SE) $=.15(.06), 95 \% \mathrm{CI}=[.04, .26]$, Figure 4C), and a supra-threshold effect of treatment $\left(\mathrm{t}_{49.09}=1.78, \mathrm{p}=.081\right.$, Estimate $(\mathrm{SE})=.22(.06), 95 \%$ $\mathrm{CI}=[-.03, .46])$, there was a significant interaction between treatment and broadband aperiodic power on CA $\left(\mathrm{t}_{432.96}=-2.70, \mathrm{p}=.007\right.$, Estimate(SE) $=-.28(.10), 95 \% \mathrm{CI}=[-.48,-.08]$, Figure 4B). The interaction indicates that oxytocin modulated the effect of broadband aperiodic power on communicative adjustment. Stronger broadband aperiodic power in vPFC was associated with stronger communicative adjustments for those participants who received oxytocin intranasal spray $\left(\mathrm{t}_{404}=2.73, \mathrm{p}=.007\right.$, Estimate $(\mathrm{SE})=.15(.06), 95 \% \mathrm{CI}=$ $[.04, .26])$. This effect was not significant for those participants who received placebo $\left(t_{432}=\right.$ -1.46, $\mathrm{p}=.146$, Estimate(SE) = -.13(.09), 95\% CI $=[-.30, .04])$. Post-hoc control analyses verified the spatial and spectral specificity of the brain-behavior correlation identified in the ventral prefrontal cortex. We did not observe similar behavioral consequences when 

or beta $(15-25 \mathrm{~Hz})$ rhythmic power in PPC, and alpha power in middle occipital cortex,

3 respectively (Supplementary 4). In sum, these results indicate that the tonic oxytocin-related

$4 \quad$ upregulation of aperiodic broadband power in ventral prefrontal cortex leads to behavioral

5 consequences, as indexed by a dynamic metric of recipient design (CA(t)). 
A)

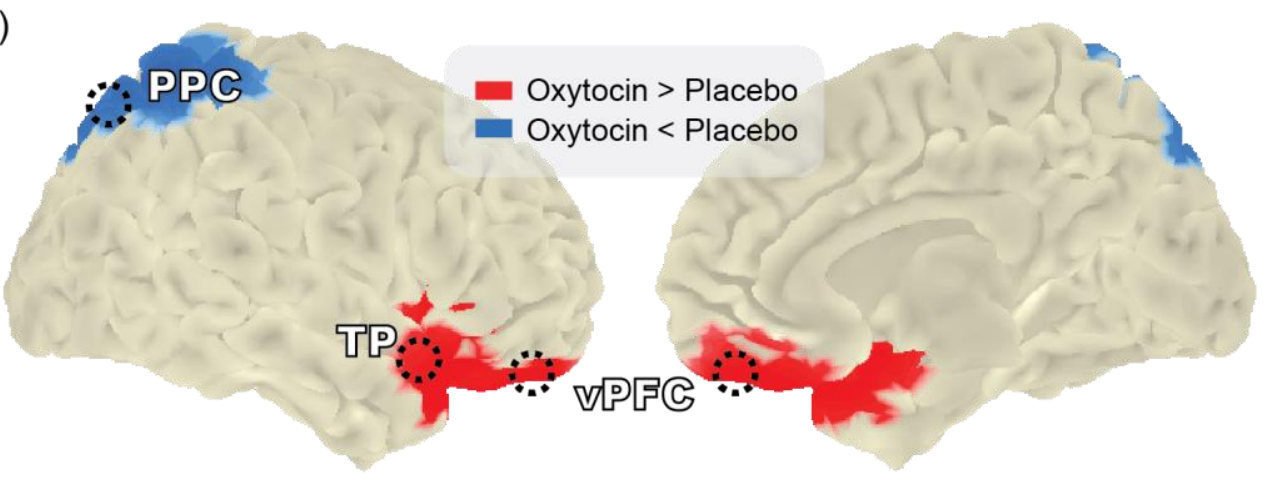

B)
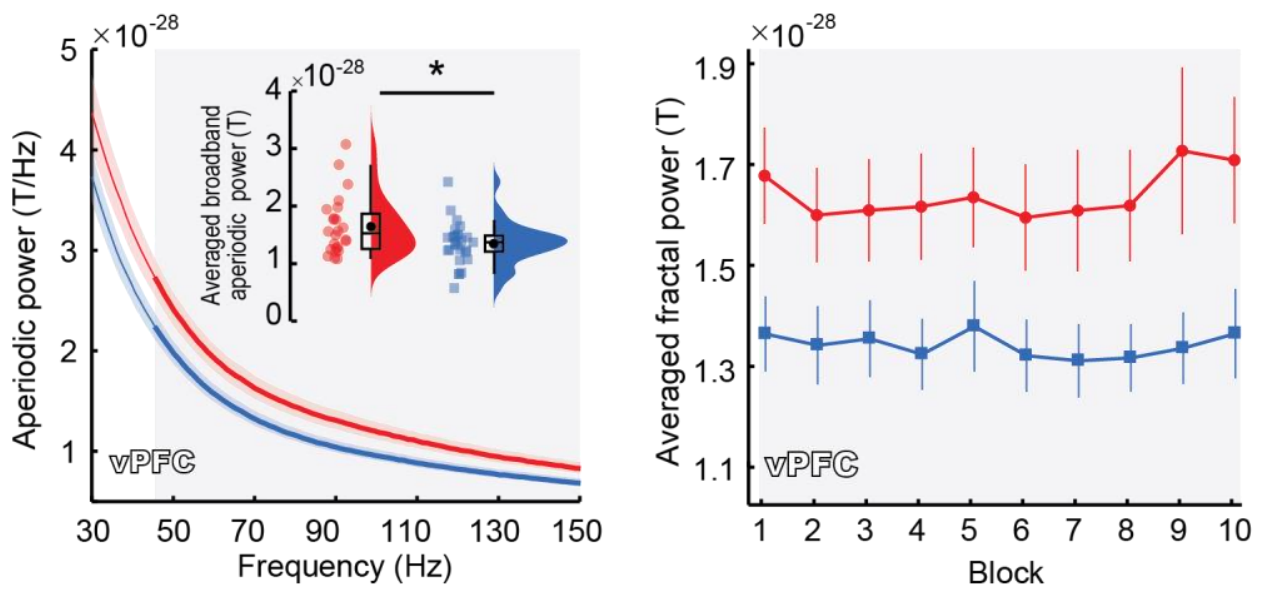

C)
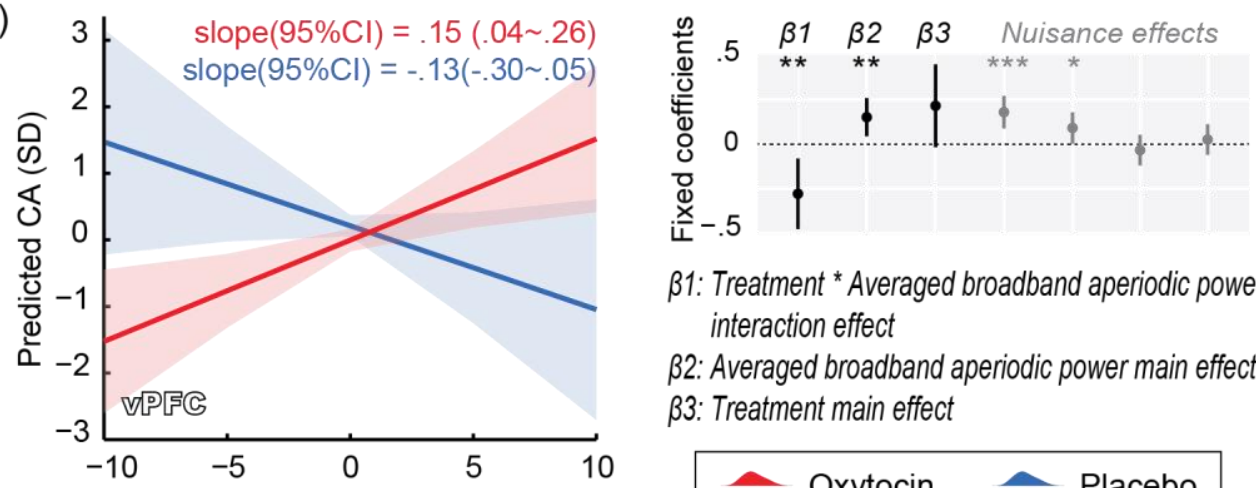

$\beta 1$ : Treatment * Averaged broadband aperiodic power interaction effect

$\beta 2$ : Averaged broadband aperiodic power main effect $\beta 3$ : Treatment main effect

\section{$\rightarrow$ Oxytocin $\rightarrow$ Placebo}

Figure 4. Electrophysiological consequences of oxytocin administration during communicative performance. A) Spatial distribution of oxytocin-related changes in aperiodic broadband power (averaged over 30-150 Hz) with local maxima in right ventral prefrontal cortex (vPFC), temporal pole (TP) and posterior parietal cortex (PPC). B) Spectral (on the right) and temporal (on the left) profile of the $\mathrm{vPFC}$ effect (mean \pm SEM, grey area indicates frequencies and time points where oxytocin and placebo groups are statistically different, $\mathrm{p}<.05$ uncorrected for multiple comparisons over frequencies and time points). Insets show spectrally averaged effects and data distributions, using the same conventions as in Figure 3. C) Oxytocin-related changes in vPFC aperiodic broadband power account for 
1 inter-participant variation in Communicative Adjustment. The upper grey panels indicate

2 estimates of the fixed coefficients $\beta 1 \sim 3$ relative to the effects specified in the legend. Error

3 bars: $95 \%$ CI of the mean. ${ }^{* * *}: \mathrm{p}<.001 ;^{* *}: \mathrm{p}<.01 ;^{*}$ : $\mathrm{p}<.05$.

5 Discussion

6 Every-day human communication requires more than habitual responses to salient social

7 stimuli (e.g. the face of an in-group member). Interlocutors accommodate to each other using

8 recipient design (Clark \& Murphy, 1982; Levinson, 2006; Tomasello, 2008). Oxytocin has

9 been found to modulate recipient design by promoting cognitive exploration (de Boer et al.,

2017; Ye et al., 2017). Here, we report behavioral and electrophysiological correlates of such oxytocinergic effect on human communicators. Behaviorally, oxytocin administration led

12 participants to progressively adapt more effectively than the placebo group to the

13 communicative behavior of the addressees. Electrophysiologically, oxytocin administration

14 induced stronger broadband aperiodic power in the right ventral prefrontal cortex, pointing

15 to increased synaptic activity (Bartoli et al., 2019; Leszczyński et al., 2020; Manning et al., 2009; Miller et al., 2014; Ray \& Maunsell, 2011). Broadband aperiodic power in the ventral

17 prefrontal cortex was positively correlated with the magnitude of communicative adjustment

18 in the oxytocin group, but not in the placebo group. These findings qualify how oxytocin

19 modulates recipient design, and suggest a neurophysiological mechanism supporting that

20 modulation. Oxytocin adaptively regulates recipient design by boosting explorative

21 adjustments during early stages of the interaction, then reducing those adjustments to match

22 the actual demands of the communicative interaction. Correspondingly, oxytocin upregulates 
state-related activity in a cortical region known to guide communicative behavior by updating knowledge about an interlocutor (Stolk et al., 2015).

\section{Oxytocin Modulates Dynamics of Recipient Design}

By using a new behavioral measure, Communicative Adjustment (CA(t)), we could quantify the fine-grained dynamics of recipient design adjustment to the child and adult presumed addressees. One of the main findings of this study is that oxytocin administration led to larger within-subject variation of $\mathrm{CA}(\mathrm{t})$ in the first half of the experiment, followed by a reduction of CA(t) variation in the second half of the experiment. This observation suggests that, in the initial stages of the communicative interaction, oxytocin increased exploration of different adjustments to the two presumed addressees, followed by a convergence of the communicative adjustments directed to those addressees. It is known that communicators spontaneously integrate prior knowledge about their interlocutor with the ongoing communicative experience (Brennan et al., 2010; Clark \& Krych, 2004; Hawkins et al., 2021;

Kuhlen et al., 2012; Kuhlen \& Brennan, 2010; Zhang et al., 2021). The behavioral finding of this study illustrates how oxytocin enhances that integration and facilitates the implementation of the Gricean Maxim of Quantity, namely producing utterances that convey no more information than necessary (Blokpoel et al., 2012; Brennan \& Clark, 1996; de Ruiter et al., 2010; Galati \& Brennan, 2010; Garrod \& Anderson, 1987; Grice, 1975; Levinson, 2000; Liu et al., 2019; Yoon \& Brown-Schmidt, 2018). More generally, the finding supports the notion that oxytocin promotes exploration not only of other social agents (e.g. in-group 
members), but also of the conceptual space supporting social interactions (de Boer et al.,

2 2017; Ye et al., 2017).

3 Collateral findings from control analyses rule out a number of alternative interpretations. At

4 the beginning of the experiment, participants from both oxytocin and placebo groups

5 revealed a positive communicative adjustment, an indication that oxytocin did not modify

6 participants' initial belief of interacting with addressees of differing communicative abilities.

7 It could be argued that oxytocin reduced participants' prosocial motivation (De Dreu, 2012;

8 De Dreu et al., 2011; Declerck et al., 2020; Hurlemann \& Marsh, 2017; Luo et al., 2017; Muroy

9 et al., 2016; Nave et al., 2015). That possibility is not compatible with the observation that the oxytocin group showed larger post-error communicative adjustments than the placebo group. Other control analyses rule out the possibility that the differential dynamics of communicative adjustments in the oxytocin and placebo groups resulted from betweengroup differences in social-cognitive traits (e.g. social anxiety and empathy), endogenous hormone level (cortisol and testosterone), or evaluation of the addressees' abilities. Furthermore, the effect of oxytocin was specific to communicative components of the participants' behavior, being absent from instrumental components of the movement (e.g. time on non-target-field, Supplementary 2).

\section{Oxytocin Modulates State-related Ventral Prefrontal Activity}

We observed that oxytocin induced persistently stronger aperiodic activity in vPFC, over a

20 broad spectral (30-150 Hz) and temporal range (throughout all experimental blocks). It has 
been argued that aperiodic power reflects action potentials of a neuronal ensemble, contributing to frequencies all over the spectrum (broadband effect), possibly leading to changes in cortical state (Bartoli et al., 2019; Bastos et al., 2018; Buzsaki \& Schomburg, 2015;

Leszczyński et al., 2020; Manning et al., 2009; Miller et al., 2009, 2014; Pettersen et al., 2014;

Ray et al., 2008; Ray \& Maunsell, 2011; Thivierge \& Cisek, 2008; Voytek et al., 2015). Furthermore, oxytocin administration in acute rat hippocampal slices leads to upregulation of fast-spiking interneurons and increases fidelity of spike transmission (Owen et al., 2013). This neurophysiological mechanism could increase signal-to-noise in neuronal ensembles responsible for sensing and integrating social information (Gangopadhyay et al., 2021), leading to increased broadband aperiodic power. The long-lasting oxytocinergic effect on aperiodic power might be related to the relatively long half-life and slow degradation of this neuropeptide (Bethlehem et al., 2013; Ludwig \& Leng, 2006), although it remains to be seen whether similar effects can be evoked by endogenous oxytocin release triggering both synaptic and non-synaptic events, such as dendritic calcium spikes that profoundly contributes to the MEG signal (Brown et al., 2020; Buzsáki et al., 2012; Ludwig \& Leng, 2006). It is known that lesion of the medial aspect of vPFC impairs recipient design, as indexed by communicators' ability to tune their communicative actions to prior knowledge and ongoing behaviors of an addressee (Stolk et al., 2015). Furthermore, vPFC is known to support mental state inference and trait attribution (Frith \& Frith, 2006; Frith \& Frith, 2003; Gallotti \& Frith, 2013; Van Overwalle, 2011; Van Overwalle \& Baetens, 2009), as well as to construct and update associations between stimuli and (social) contextual frames (Bertossi et al., 2016; 
1 Krueger et al., 2009; Spalding et al., 2015; Zink et al., 2008). Here, we extend that knowledge

2 by showing that the contribution of $\mathrm{VPFC}$ to recipient design is proportional to the oxytocinergic upregulation of broadband aperiodic activity. Accordingly, the current finding emphasizes the importance of oxytocinergic tone in vPFC for dynamically integrating prior knowledge with on-going communicative experience. Given the presence of oxytocin receptors in the post-orbital gyrus in human brain (Boccia et al., 2013), it is possible that oxytocin regulates recipient design via a direct impact on vPFC neural activity. However, oxytocin effects are also mediated through other neurotransmitter systems, such as the dopaminergic and the serotoninergic systems, influencing several prefrontal-amygdala circuits (Froemke \& Young, 2021; Gangopadhyay et al., 2021; Love, 2014; Ma et al., 2016; Martins et al., 2021; Quintana et al., 2019; Sripada et al., 2013; Striepens et al., 2014). Future studies might differentiate these potential mechanisms with high-precision M/EEG (Seeber et al., 2019; Tzovara et al., 2019) and newly developed algorithms for source reconstruction (Krishnaswamy et al., 2017; Pizzo et al., 2019) that are able to disentangle activities from deeper limbic structures.

It is known that the vPFC region is particularly vulnerable to non-neural contributions to the MEG signal (Carl et al., 2012). It might be argued that the between-groups differences in MEG signal are partially due to systematic between-groups differences in participants' head size, position, or motion during the task. However, there were no major systematic differences in those parameters between groups, and the analytical procedures removed contributions of those parameters from the neural signals (Supplementary 3). Furthermore, despite the lack 
of gaze-related data due to testing time constraints, we estimated MEG consequences of eye

2 movements by source-reconstructing ocular muscles signals (Supplementary 3) and removed

3 it from inter-subject variance with linear regression. This approach offered a relatively

4 stringent control against eye movements confounds, at the cost of reduced sensitivity to task-

5 related effects. For instance, this control analysis largely removed the oxytocin-related effect

6 on aperiodic power observed in the right temporal pole, leaving only an effect at high

7 frequency (>120 Hz, Supplementary 3).

8 The MEG analyses focused on effects spanning several seconds, from two seconds before trial

9 onset until the start of the communicator's response. It might be argued that this choice

10 misses the opportunity to take advantage of the high temporal resolution of MEG. In fact, this

11 study uses the temporal resolution of MEG to estimate the spectral distribution of neural

12 effects evoked by the experimental interventions. We chose to extract those estimates from

13 a relatively long temporal window because oxytocin administration and referential

14 communication are both known to evoke state-related effects (Bethlehem et al., 2013;

15 Ludwig \& Leng, 2006; Stolk, Verhagen, et al., 2013). However, to ensure a fair comparison

16 between the oxytocin and placebo groups, the spatial filter for source reconstruction was

17 computed using used matched lengths of data based on all trial epochs (Supplementary 3).

\section{Conclusion}

19 Our findings indicate that oxytocin leads to faster recipient design, pushing participants to

20 consider recent communicative history and downweight their expectations about the 
1 abilities of a child addressee. The finding support the notion that oxytocin promotes

2 exploration of the conceptual space supporting communicative interactions (de Boer et al.,

3 2017; Ye et al., 2017). This study opens the way to test whether the state-related

4 oxytocinergic upregulation of $\mathrm{vPFC}$ aperiodic power provides a general mechanism

5 supporting communication during multimodal linguistic face-to-face interactions (Holler \&

6 Levinson, 2019; Levinson, 2006). 


\section{Reference}

Arueti, M., Perach-Barzilay, N., Tsoory, M. M., Berger, B., Getter, N., \& Shamay-Tsoory, S. G. (2013). When Two Become One: The Role of Oxytocin in Interpersonal Coordination and Cooperation. Journal of Cognitive Neuroscience, 25(9), 1418-1427. https://doi.org/10.1162/jocn_a_00400

Baron-Cohen, S., Richler, J., Bisarya, D., Gurunathan, N., \& Wheelwright, S. (2003). The systemizing quotient: an investigation of adults with Asperger syndrome or highfunctioning autism, and normal sex differences. Philosophical Transactions of the Royal Society B: Biological Sciences, 358(1430), 361-374. https://doi.org/10.1098/rstb.2002.1206

Baron-Cohen, S., \& Wheelwright, S. (2004). The empathy quotient: an investigation of adults with Asperger syndrome or high functioning autism, and normal sex differences. Journal of Autism and Developmental Disorders, 34(2), 163-175. https://doi.org/10.1023/b:jadd.0000022607.19833.00

Bartoli, E., Bosking, W., Chen, Y., Li, Y., Sheth, S. A., Beauchamp, M. S., Yoshor, D., \& Foster, B. L. (2019). Functionally Distinct Gamma Range Activity Revealed by Stimulus Tuning in Human Visual Cortex. Current Biology, 29(20), 3345-3358.e7. https://doi.org/10.1016/j.cub.2019.08.004

Bartz, J. A., Zaki, J., Bolger, N., \& Ochsner, K. N. (2011). Social effects of oxytocin in humans: context and person matter. Trends in Cognitive Sciences, 15(7), 301-309. https://doi.org/10.1016/j.tics.2011.05.002

Bastos, A. M., Loonis, R., Kornblith, S., Lundqvist, M., \& Miller, E. K. (2018). Laminar recordings in frontal cortex suggest distinct layers for maintenance and control of working memory. Proceedings of the National Academy of Sciences, 115(5), 11171122.

Bates, D., Mächler, M., Bolker, B., \& Walker, S. (2015). Fitting Linear Mixed-Effects Models Using lme4. Journal of Statistical Software, 67(1), 1-48. https://doi.org/10.18637/jss.v067.i01

Bertossi, E., Aleo, F., Braghittoni, D., \& Ciaramelli, E. (2016). Stuck in the here and now: Construction of fictitious and future experiences following ventromedial prefrontal damage. Neuropsychologia, 81, 107-116. https://doi.org/10.1016/j.neuropsychologia.2015.12.015

Bethlehem, R. A. I., van Honk, J., Auyeung, B., \& Baron-Cohen, S. (2013). Oxytocin, brain physiology, and functional connectivity: A review of intranasal oxytocin fMRI studies. Psychoneuroendocrinology, 38(7), 962-974. https://doi.org/10.1016/j.psyneuen.2012.10.011

Blokpoel, M., van Kesteren, M., Stolk, A., Haselager, P., Toni, I., \& Van Rooij, I. (2012). Recipient design in human communication: simple heuristics or perspective taking? Frontiers in Human Neuroscience, 6. https://doi.org/10.3389/fnhum.2012.00253

Boccia, M. L., Petrusz, P., Suzuki, K., Marson, L., \& Pedersen, C. A. (2013). 
Immunohistochemical localization of oxytocin receptors in human brain. Neuroscience, 253, 155-164. https://doi.org/10.1016/j.neuroscience.2013.08.048

Bolar, K. (2019). STAT: Interactive Document for Working with Basic Statistical Analysis (Version 0.1.0) [Computer software]. https://CRAN.R-project.org/package=STAT

Brand, R. J., Baldwin, D. A., \& Ashburn, L. A. (2002). Evidence for 'motionese': modifications in mothers' infant-directed action. Developmental Science, 5(1), 72-83. https://doi.org/10.1111/1467-7687.00211

Brennan, S. E., \& Clark, H. H. (1996). Conceptual pacts and lexical choice in conversation. Journal of Experimental Psychology: Learning, Memory, and Cognition, 22(6), 14821493. https://doi.org/10.1037/0278-7393.22.6.1482

Brennan, S. E., Galati, A., \& Kuhlen, A. K. (2010). Chapter 8 - Two Minds, One Dialog: Coordinating Speaking and Understanding. In B. H. Ross (Ed.), Psychology of Learning and Motivation (Vol. 53, pp. 301-344). Academic Press. https://doi.org/10.1016/S0079-7421(10)53008-1

Brinkman, L., Stolk, A., Dijkerman, H. C., Lange, F. P. de, \& Toni, I. (2014). Distinct Roles for Alpha- and Beta-Band Oscillations during Mental Simulation of Goal-Directed Actions. Journal of Neuroscience, 34(44), 14783-14792. https://doi.org/10.1523/JNEUROSCI.2039-14.2014

Brodsky, P., \& Edelman, S. (n.d.). Characterizing Motherese: On the Computational Structure of Child-Directed Language. 7.

Brown, C. H., Ludwig, M., Tasker, J. G., \& Stern, J. E. (2020). Somato-dendritic vasopressin and oxytocin secretion in endocrine and autonomic regulation. Journal of Neuroendocrinology, 32(6), e12856. https://doi.org/10.1111/jne.12856

Buzsáki, G., Anastassiou, C. A., \& Koch, C. (2012). The origin of extracellular fields and currents - EEG, ECoG, LFP and spikes. Nature Reviews Neuroscience, 13(6), 407420. https://doi.org/10.1038/nrn3241

Buzsaki, G., \& Schomburg, E. W. (2015). What does gamma coherence tell us about interregional neural communication? Nature Neuroscience, 18(4), 484-489. https://doi.org/10.1038/nn.3952

Cacioppo, J. T., Petty, R. E., \& Kao, C. F. (1984). The efficient assessment of need for cognition. Journal of Personality Assessment, 48(3), 306-307. https://doi.org/10.1207/s15327752jpa4803_13

Campisi, E., \& Özyürek, A. (2013). Iconicity as a communicative strategy: Recipient design in multimodal demonstrations for adults and children. Journal of Pragmatics, 47(1), 14-27. https://doi.org/10.1016/j.pragma.2012.12.007

Carl, C., Açık, A., König, P., Engel, A. K., \& Hipp, J. F. (2012). The saccadic spike artifact in MEG. NeuroImage, 59(2), 1657-1667. https://doi.org/10.1016/j.neuroimage.2011.09.020

Chaoul, A. I., \& Siegel, M. (2020). Distinct cortical correlation structures of fractal and oscillatory neuronal activity. BioRxiv, 2020.12.10.415315. https://doi.org/10.1101/2020.12.10.415315 
Clark, H. H., \& Krych, M. A. (2004). Speaking while monitoring addressees for understanding. Journal of Memory and Language, 50(1), 62-81. https://doi.org/10.1016/j.jml.2003.08.004

Clark, H. H., \& Murphy, G. L. (1982). Audience Design in Meaning and Reference. In J.-F. Le Ny \& W. Kintsch (Eds.), Advances in Psychology (Vol. 9, pp. 287-299). North-Holland. https://doi.org/10.1016/S0166-4115(09)60059-5

Davis, M. H. (1983). Measuring individual differences in empathy: Evidence for a multidimensional approach. Journal of Personality and Social Psychology, 44(1), 113126. https://doi.org/10.1037/0022-3514.44.1.113

de Boer, M., Kokal, I., Blokpoel, M., Liu, R., Stolk, A., Roelofs, K., van Rooij, I., \& Toni, I. (2017). Oxytocin modulates human communication by enhancing cognitive exploration. Psychoneuroendocrinology, 86, 64-72. https://doi.org/10.1016/j.psyneuen.2017.09.010

de Bruijn, E. R. A., Ruissen, M. I., \& Radke, S. (2017). Electrophysiological correlates of oxytocin-induced enhancement of social performance monitoring. Social Cognitive and Affective Neuroscience, 12(10), 1668-1677. https://doi.org/10.1093/scan/nsx094

De Coster, L., Lin, L., Mathalon, D. H., \& Woolley, J. D. (2019). Neural and behavioral effects of oxytocin administration during theory of mind in schizophrenia and controls: a randomized control trial. Neuropsychopharmacology, 44(11), 1925-1931. https://doi.org/10.1038/s41386-019-0417-5

De Dreu, C. K. W. (2012). Oxytocin modulates cooperation within and competition between groups: an integrative review and research agenda. Hormones and Behavior, 61(3), 419-428. https://doi.org/10.1016/j.yhbeh.2011.12.009

De Dreu, C. K. W., Baas, M., \& Boot, N. C. (2015). Oxytocin enables novelty seeking and creative performance through upregulated approach: evidence and avenues for future research. Wiley Interdisciplinary Reviews. Cognitive Science, 6(5), 409-417. https://doi.org/10.1002/wcs.1354

De Dreu, C. K. W., Baas, M., Roskes, M., Sligte, D. J., Ebstein, R. P., Chew, S. H., Tong, T., Jiang, Y., Mayseless, N., \& Shamay-Tsoory, S. G. (2014). Oxytonergic circuitry sustains and enables creative cognition in humans. Social Cognitive and Affective Neuroscience, 9(8), 1159-1165. https://doi.org/10.1093/scan/nst094

De Dreu, C. K. W., Greer, L. L., Van Kleef, G. A., Shalvi, S., \& Handgraaf, M. J. J. (2011). Oxytocin promotes human ethnocentrism. Proceedings of the National Academy of Sciences of the United States of America, 108(4), 1262-1266. https://doi.org/10.1073/pnas.1015316108

de Ruiter, J. P. de, Noordzij, M. L., Newman-Norlund, S., Hagoort, P., \& Toni, I. (2006). On the origin of intentions. Oxford University Press. https://oxford.universitypressscholarship.com/view/10.1093/acprof:oso/9780199 231447.001.0001/acprof-9780199231447-chapter-26

de Ruiter, J. P. de, Noordzij, M. L., Newman-Norlund, S., Newman-Norlund, R., Hagoort, P., 
Levinson, S. C., \& Toni, I. (2010). Exploring the cognitive infrastructure of communication. Interaction Studies, 11(1), 51-77. https://doi.org/10.1075/is.11.1.05rui

Declerck, C. H., Boone, C., Pauwels, L., Vogt, B., \& Fehr, E. (2020). A registered replication study on oxytocin and trust. Nature Human Behaviour, 4(6), 646-655. https://doi.org/10.1038/s41562-020-0878-x

Domes, G., Heinrichs, M., Michel, A., Berger, C., \& Herpertz, S. C. (2007). Oxytocin improves "mind-reading" in humans. Biological Psychiatry, 61(6), 731-733. https://doi.org/10.1016/j.biopsych.2006.07.015

Donoghue, T., Haller, M., Peterson, E. J., Varma, P., Sebastian, P., Gao, R., Noto, T., Lara, A. H., Wallis, J. D., Knight, R. T., Shestyuk, A., \& Voytek, B. (2020). Parameterizing neural power spectra into periodic and aperiodic components. Nature Neuroscience, 23(12), 1655-1665. https://doi.org/10.1038/s41593-020-00744-x

Festante, F., Ferrari, P. F., Thorpe, S. G., Buchanan, R. W., \& Fox, N. A. (2020). Intranasal oxytocin enhances EEG mu rhythm desynchronization during execution and observation of social action: An exploratory study. Psychoneuroendocrinology, 111, 104467. https://doi.org/10.1016/j.psyneuen.2019.104467

Festante, F., Rayson, H., Paukner, A., Kaburu, S. S. K., Toschi, G., Fox, N. A., \& Ferrari, P. F. (2021). Oxytocin promotes prosocial behavior and related neural responses in infant macaques at-risk for compromised social development. Developmental Cognitive Neuroscience, 48, 100950. https://doi.org/10.1016/j.dcn.2021.100950

Frith, C. D., \& Frith, U. (2006). The neural basis of mentalizing. Neuron, 50(4), 531-534. https://doi.org/10.1016/j.neuron.2006.05.001

Frith, U., \& Frith, C. D. (2003). Development and neurophysiology of mentalizing. Philosophical Transactions of the Royal Society of London. Series B, Biological Sciences, 358(1431), 459-473. https://doi.org/10.1098/rstb.2002.1218

Froemke, R. C., \& Young, L. J. (2021). Oxytocin, Neural Plasticity, and Social Behavior. Annual Review of Neuroscience, 44(1), 359-381. https://doi.org/10.1146/annurev-neuro102320-102847

Fussell, S. R., \& Krauss, R. M. (1989). The effects of intended audience on message production and comprehension: Reference in a common ground framework. Journal of Experimental Social Psychology, 25(3), 203-219. https://doi.org/10.1016/00221031(89)90019-X

Galati, A., \& Brennan, S. E. (2010). Attenuating information in spoken communication: For the speaker, or for the addressee? Journal of Memory and Language, 62(1), 35-51. https://doi.org/10.1016/j.jml.2009.09.002

Gallotti, M., \& Frith, C. D. (2013). Social cognition in the we-mode. Trends in Cognitive Sciences, 17(4), 160-165. https://doi.org/10.1016/j.tics.2013.02.002

Gangopadhyay, P., Chawla, M., Dal Monte, O., \& Chang, S. W. C. (2021). Prefrontal-amygdala circuits in social decision-making. Nature Neuroscience, 24(1), 5-18. https://doi.org/10.1038/s41593-020-00738-9 
Garrod, S., \& Anderson, A. (1987). Saying what you mean in dialogue: A study in conceptual and semantic co-ordination. Cognition, 27(2), 181-218. https://doi.org/10.1016/0010-0277(87)90018-7

Geenen, V., Adam, F., Baro, V., Mantanus, H., Ansseau, M., Timsit-Berthier, M., \& Legros, J. J. (1988). Inhibitory influence of oxytocin infusion on contingent negative variation and some memory tasks in normal men. Psychoneuroendocrinology, 13(5), 367-375. https://doi.org/10.1016/0306-4530(88)90043-1

Grice, P. (1975). Logic and conversation. In J. Morgan \& P. Cole (Eds.), Syntax and semantic Vol. 3: Speech acts (Vol. 3, pp. 41-58). Academic Press. http://lefft.xyz/psycholingAU16/readings/grice1975-logic-and-conversation.pdf

Grieser, D. L., \& Kuhl, P. K. (1988). Maternal speech to infants in a tonal language: Support for universal prosodic features in motherese. Developmental Psychology, 24(1), 1420. https://doi.org/10.1037/0012-1649.24.1.14

Grinevich, V., \& Stoop, R. (2018). Interplay between Oxytocin and Sensory Systems in the Orchestration of Socio-Emotional Behaviors. Neuron, 99(5), 887-904. https://doi.org/10.1016/j.neuron.2018.07.016

Gross, J., Kujala, J., Hamalainen, M., Timmermann, L., Schnitzler, A., \& Salmelin, R. (2001). Dynamic imaging of coherent sources: Studying neural interactions in the human brain. Proceedings of the National Academy of Sciences of the United States of America, 98(2), 694-699. https://doi.org/10.1073/pnas.98.2.694

Haegens, S., Nácher, V., Hernández, A., Luna, R., Jensen, O., \& Romo, R. (2011). Beta oscillations in the monkey sensorimotor network reflect somatosensory decision making. Proceedings of the National Academy of Sciences, 108(26), 10708-10713. https://doi.org/10.1073/pnas.1107297108

Halekoh, U., \& Højsgaard, S. (2014). A Kenward-Roger Approximation and Parametric Bootstrap Methods for Tests in Linear Mixed Models - The R Package pbkrtest. Journal of Statistical Software, 59(1), 1-32. https://doi.org/10.18637/jss.v059.i09

Hawkins, R. D., Franke, M., Frank, M. C., Smith, K., Griffiths, T. L., \& Goodman, N. D. (2021). From partners to populations: A hierarchical Bayesian account of coordination and convention. ArXiv:2104.05857 [Cs]. http://arxiv.org/abs/2104.05857

Holler, J., \& Levinson, S. C. (2019). Multimodal Language Processing in Human Communication. Trends in Cognitive Sciences, 23(8), 639-652. https://doi.org/10.1016/j.tics.2019.05.006

Hurlemann, R., \& Marsh, N. (2017). Deciphering the modulatory role of oxytocin in human altruism. Reviews in the Neurosciences, 28(4), 335-342. https://doi.org/10.1515/revneuro-2016-0061

Jensen, 0., \& Mazaheri, A. (2010). Shaping Functional Architecture by Oscillatory Alpha Activity: Gating by Inhibition. Frontiers in Human Neuroscience, 4. https://doi.org/10.3389/fnhum.2010.00186

Kapetaniou, G. E., Reinhard, M. A., Christian, P., Jobst, A., Tobler, P. N., Padberg, F., \& Soutschek, A. (2021). The role of oxytocin in delay of gratification and flexibility in 
non-social decision making. ELife, 10. https://doi.org/10.7554/eLife.61844

Klimesch, W. (2012). $\alpha$-band oscillations, attention, and controlled access to stored information. Trends in Cognitive Sciences, 16(12), 606-617. https://doi.org/10.1016/j.tics.2012.10.007

Krishnaswamy, P., Obregon-Henao, G., Ahveninen, J., Khan, S., Babadi, B., Iglesias, J. E., Hämäläinen, M. S., \& Purdon, P. L. (2017). Sparsity enables estimation of both subcortical and cortical activity from MEG and EEG. Proceedings of the National Academy of Sciences of the United States of America, 114(48), E10465-E10474. https://doi.org/10.1073/pnas.1705414114

Krueger, F., Barbey, A. K., \& Grafman, J. (2009). The medial prefrontal cortex mediates social event knowledge. Trends in Cognitive Sciences, 13(3), 103-109. https://doi.org/10.1016/j.tics.2008.12.005

Kuhlen, A. K., \& Brennan, S. E. (2010). Anticipating Distracted Addressees: How Speakers' Expectations and Addressees' Feedback Influence Storytelling. Discourse Processes, 47(7), 567-587. https://doi.org/10.1080/01638530903441339

Kuhlen, A. K., Galati, A., \& Brennan, S. E. (2012). Gesturing integrates top-down and bottomup information: Joint effects of speakers' expectations and addressees' feedback. Language and Cognition, 4(1), 17-41. https://doi.org/10.1515/langcog-2012-0002

Lenth, R. V., Buerkner, P., Herve, M., Love, J., Riebl, H., \& Singmann, H. (2021). emmeans: Estimated Marginal Means, aka Least-Squares Means (Version 1.5.5-1) [Computer software]. https://CRAN.R-project.org/package=emmeans

Leszczyński, M., Barczak, A., Kajikawa, Y., Ulbert, I., Falchier, A. Y., Tal, I., Haegens, S., Melloni, L., Knight, R. T., \& Schroeder, C. E. (2020). Dissociation of broadband high-frequency activity and neuronal firing in the neocortex. Science Advances, 6(33), eabb0977. https://doi.org/10.1126/sciadv.abb0977

Levinson, S. C. (2000). On the Notion of a Generalized Conversational Implicature. In Presumptive Meanings: The Theory of Generalized Conversational Implicature (pp. 11-72). A Bradford Book. ttps://doi.org/10.7551/mitpress/5526.003.0007

Levinson, S. C. (2006). On the Human "Interaction Engine." In N. J. Enfield \& S. C. Levinson (Eds.), Roots of Human Sociality: Culture, cognition and interaction (1st ed., pp. 3969). Routledge. https://doi.org/10.4324/9781003135517-3

Levy, J., Goldstein, A., \& Feldman, R. (2017). Perception of social synchrony induces motherchild gamma coupling in the social brain. Social Cognitive and Affective Neuroscience, 12(7), 1036-1046. https://doi.org/10.1093/scan/nsx032

Levy, J., Goldstein, A., Influs, M., Masalha, S., Zagoory-Sharon, O., \& Feldman, R. (2016). Adolescents growing up amidst intractable conflict attenuate brain response to pain of outgroup. Proceedings of the National Academy of Sciences of the United States of America, 113(48), 13696-13701. https://doi.org/10.1073/pnas.1612903113

Levy, J., Goldstein, A., Zagoory-Sharon, O., Weisman, O., Schneiderman, I., EidelmanRothman, M., \& Feldman, R. (2016). Oxytocin selectively modulates brain response to stimuli probing social synchrony. NeuroImage, 124, 923-930. 
https://doi.org/10.1016/j.neuroimage.2015.09.066

Liebowitz, M. R. (1987). Social Phobia. Anxiety, 22, 141-173. https://doi.org/10.1159/000414022

Liu, R., Bögels, S., Bird, G., Medendorp, P., \& Toni, I. (2019). Hierarchical integration of communicative and visuospatial perspective-taking demands in sensorimotor control of referential pointing. PsyArXiv. https://doi.org/10.31234/osf.io/htvqa

Liu, Y., Sheng, F., Woodcock, K. A., \& Han, S. (2013). Oxytocin effects on neural correlates of self-referential processing. Biological Psychology, 94(2), 380-387. https://doi.org/10.1016/j.biopsycho.2013.08.003

Love, T. M. (2014). Oxytocin, motivation and the role of dopamine. Pharmacology, Biochemistry, and Behavior, 119, 49-60. https://doi.org/10.1016/j.pbb.2013.06.011

Ludwig, M., \& Leng, G. (2006). Dendritic peptide release and peptide-dependent behaviours. Nature Reviews. Neuroscience, 7(2), 126-136. https://doi.org/10.1038/nrn1845

Luo, S., Zhang, T., Li, W., Yu, M., Hein, G., \& Han, S. (2019). Interactions between oxytocin receptor gene and intergroup relationship on empathic neural responses to others' pain. Social Cognitive and Affective Neuroscience, 14(5), 505-517. https://doi.org/10.1093/scan/nsz029

Luo, S., Zhu, Y., Xu, Y., \& Kong, Q. (2017). The oxytocinergic system modulates sadistic context-dependent empathy in humans. Scientific Reports, 7(1), 12463. https://doi.org/10.1038/s41598-017-12671-2

Ma, Y., Shamay-Tsoory, S., Han, S., \& Zink, C. F. (2016). Oxytocin and Social Adaptation: Insights from Neuroimaging Studies of Healthy and Clinical Populations. Trends in Cognitive Sciences, 20(2), 133-145. https://doi.org/10.1016/j.tics.2015.10.009

Manning, J. R., Jacobs, J., Fried, I., \& Kahana, M. J. (2009). Broadband Shifts in Local Field Potential Power Spectra Are Correlated with Single-Neuron Spiking in Humans. Journal of Neuroscience, 29(43), 13613-13620. https://doi.org/10.1523/JNEUROSCI.2041-09.2009

Maris, E., \& Oostenveld, R. (2007). Nonparametric statistical testing of EEG- and MEG-data. Journal of Neuroscience Methods, 164(1), 177-190. https://doi.org/10.1016/j.jneumeth.2007.03.024

Martins, D., Dipasquale, O., \& Paloyelis, Y. (2021). Oxytocin modulates local topography of human functional connectome in healthy men at rest. Communications Biology, 4(1), 1-14. https://doi.org/10.1038/s42003-020-01610-z

Miller, K. J., Honey, C. J., Hermes, D., Rao, R. P., denNijs, M., \& Ojemann, J. G. (2014). Broadband changes in the cortical surface potential track activation of functionally diverse neuronal populations. NeuroImage, 85, 711-720. https://doi.org/10.1016/j.neuroimage.2013.08.070

Miller, K. J., Sorensen, L. B., Ojemann, J. G., \& Nijs, M. den. (2009). Power-Law Scaling in the Brain Surface Electric Potential. PLOS Computational Biology, 5(12), e1000609. https://doi.org/10.1371/journal.pcbi.1000609 
Mu, Y., Guo, C., \& Han, S. (2016). Oxytocin enhances inter-brain synchrony during social coordination in male adults. Social Cognitive and Affective Neuroscience, 11(12), 1882-1893. https://doi.org/10.1093/scan/nsw106

Murillo Oosterwijk, A., Boer, M. de, Stolk, A., Hartmann, F., Toni, I., \& Verhagen, L. (2017). Communicative knowledge pervasively influences sensorimotor computations. Scientific Reports, 7(1), 4268. https://doi.org/10.1038/s41598-017-04442-w

Muroy, S. E., Long, K. L. P., Kaufer, D., \& Kirby, E. D. (2016). Moderate Stress-Induced Social Bonding and Oxytocin Signaling are Disrupted by Predator Odor in Male Rats. Neuropsychopharmacology, 41(8), 2160-2170. https://doi.org/10.1038/npp.2016.16

Nave, G., Camerer, C., \& McCullough, M. (2015). Does Oxytocin Increase Trust in Humans? A Critical Review of Research. Perspectives on Psychological Science: A Journal of the Association for Psychological Science, 10(6), 772-789. https://doi.org/10.1177/1745691615600138

Newman-Norlund, S. E., Noordzij, M. L., Newman-Norlund, R. D., Volman, I. A. C., Ruiter, J. P. de, Hagoort, P., \& Toni, I. (2009). Recipient design in tacit communication. Cognition, 111(1), 46-54. https://doi.org/10.1016/j.cognition.2008.12.004

Nolte, G. (2003). The magnetic lead field theorem in the quasi-static approximation and its use for magnetoencephalography forward calculation in realistic volume conductors. Physics in Medicine and Biology, 48(22), 3637-3652. https://doi.org/10.1088/0031-9155/48/22/002

Noordzij, M. L., Newman-Norlund, S. E., De Ruiter, J. P., Hagoort, P., Levinson, S. C., \& Toni, I. (2009). Brain mechanisms underlying human communication. Frontiers in Human Neuroscience, 3. https://doi.org/10.3389/neuro.09.014.2009

Noordzij, M. L., Newman-Norlund, S. E., De Ruiter, J. P., Hagoort, P., Levinson, S. C., \& Toni, I. (2010). Neural Correlates of Intentional Communication. Frontiers in Neuroscience, 4. https://doi.org/10.3389/fnins.2010.00188

O'Neill, M., Bard, K. A., Linnell, M., \& Fluck, M. (2005). Maternal gestures with 20-month-old infants in two contexts. Developmental Science, 8(4), 352-359. https://doi.org/10.1111/j.1467-7687.2005.00423.x

Oostenveld, R., Fries, P., Maris, E., \& Schoffelen, J.-M. (2010). FieldTrip: Open Source Software for Advanced Analysis of MEG, EEG, and Invasive Electrophysiological Data. Computational Intelligence and Neuroscience, 2011, e156869. https://doi.org/10.1155/2011/156869

Owen, S. F., Tuncdemir, S. N., Bader, P. L., Tirko, N. N., Fishell, G., \& Tsien, R. W. (2013). Oxytocin enhances hippocampal spike transmission by modulating fast-spiking interneurons. Nature, 500(7463), 458-462. https://doi.org/10.1038/nature12330

Perry, A., Bentin, S., Shalev, I., Israel, S., Uzefovsky, F., Bar-On, D., \& Ebstein, R. P. (2010). Intranasal oxytocin modulates EEG mu/alpha and beta rhythms during perception of biological motion. Psychoneuroendocrinology, 35(10), 1446-1453. https://doi.org/10.1016/j.psyneuen.2010.04.011 
Pettersen, K. H., Lindén, H., Tetzlaff, T., \& Einevoll, G. T. (2014). Power Laws from Linear Neuronal Cable Theory: Power Spectral Densities of the Soma Potential, Soma Membrane Current and Single-Neuron Contribution to the EEG. PLOS Computational Biology, 10(11), e1003928. https://doi.org/10.1371/journal.pcbi.1003928

Piva, M., \& Chang, S. W. C. (2018). An integrated framework for the role of oxytocin in multistage social decision-making. American Journal of Primatology, 80(10), e22735. https://doi.org/10.1002/ajp.22735

Pizzo, F., Roehri, N., Medina Villalon, S., Trébuchon, A., Chen, S., Lagarde, S., Carron, R., Gavaret, M., Giusiano, B., McGonigal, A., Bartolomei, F., Badier, J. M., \& Bénar, C. G. (2019). Deep brain activities can be detected with magnetoencephalography. Nature Communications, 10(1), 971. https://doi.org/10.1038/s41467-019-08665-5

Quintana, D. S., Rokicki, J., van der Meer, D., Alnæs, D., Kaufmann, T., Córdova-Palomera, A., Dieset, I., Andreassen, O. A., \& Westlye, L. T. (2019). Oxytocin pathway gene networks in the human brain. Nature Communications, 10(1), 668. https://doi.org/10.1038/s41467-019-08503-8

R Core Team. (2009). $R$ : A language and environment for statistical computing. $R$ Foundation for Statistical Computing (Version 3.6.1) [Computer software]. https://www.R-project.org/

Radke, S., \& de Bruijn, E. R. A. (2015). Does oxytocin affect mind-reading? A replication study. Psychoneuroendocrinology, 60, 75-81. https://doi.org/10.1016/j.psyneuen.2015.06.006

Radke, S., Volman, I., Kokal, I., Roelofs, K., de Bruijn, E. R. A., \& Toni, I. (2017). Oxytocin reduces amygdala responses during threat approach. Psychoneuroendocrinology, 79, 160-166. https://doi.org/10.1016/j.psyneuen.2017.02.028

Ray, S., Crone, N. E., Niebur, E., Franaszczuk, P. J., \& Hsiao, S. S. (2008). Neural Correlates of High-Gamma Oscillations (60-200 Hz) in Macaque Local Field Potentials and Their Potential Implications in Electrocorticography. Journal of Neuroscience, 28(45), 11526-11536. https://doi.org/10.1523/JNEUROSCI.2848-08.2008

Ray, S., \& Maunsell, J. H. R. (2011). Different Origins of Gamma Rhythm and High-Gamma Activity in Macaque Visual Cortex. PLoS Biology, 9(4). https://doi.org/10.1371/journal.pbio.1000610

Ruissen, M. I., \& de Bruijn, E. R. A. (2015). Is it me or is it you? Behavioral and electrophysiological effects of oxytocin administration on self-other integration during joint task performance. Cortex, 70, 146-154. https://doi.org/10.1016/j.cortex.2015.04.017

Sacks, H., Schegloff, E. A., \& Jefferson, G. (1978). chapter 1 - A Simplest Systematics for the Organization of Turn Taking for Conversation**This chapter is a variant version of "A Simplest Systematics for the Organization of Turn-Taking for Conversation," which was printed in Language, 50, 4 (1974), pp. 696-735. An earlier version of this paper was presented at the conference on "Sociology of Language and Theory of Speech Acts," held at the Centre for Interdisciplinary Research of the University of Bielefeld, 
Germany. We thank Dr. Anita Pomerantz and Mr. Richard Faumann for pointing out to us a number of errors in the text. In J. Schenkein (Ed.), Studies in the Organization of Conversational Interaction (pp. 7-55). Academic Press. https://doi.org/10.1016/B978-0-12-623550-0.50008-2

Schoffelen, J.-M., Oostenveld, R., \& Fries, P. (2008). Imaging the human motor system's betaband synchronization during isometric contraction. NeuroImage, 41(2), 437-447. https://doi.org/10.1016/j.neuroimage.2008.01.045

Seeber, M., Cantonas, L.-M., Hoevels, M., Sesia, T., Visser-Vandewalle, V., \& Michel, C. M. (2019). Subcortical electrophysiological activity is detectable with high-density EEG source imaging. Nature Communications, 10(1), 753. https://doi.org/10.1038/s41467-019-08725-w

Shamay-Tsoory, S. G., \& Abu-Akel, A. (2016). The Social Salience Hypothesis of Oxytocin. Biological Psychiatry, 79(3), 194-202. https://doi.org/10.1016/j.biopsych.2015.07.020

Soriano, J. R., Daniels, N., Prinsen, J., \& Alaerts, K. (2020). Intranasal oxytocin enhances approach-related EEG frontal alpha asymmetry during engagement of direct eye contact. Brain Communications, 2(2). https://doi.org/10.1093/braincomms/fcaa093

Spalding, K. N., Jones, S. H., Duff, M. C., Tranel, D., \& Warren, D. E. (2015). Investigating the neural correlates of schemas: Ventromedial prefrontal cortex is necessary for normal schematic influence on memory. Journal of Neuroscience, 35(47), 1574615751. Scopus. https://doi.org/10.1523/JNEUROSCI.2767-15.2015

Spengler, F. B., Scheele, D., Marsh, N., Kofferath, C., Flach, A., Schwarz, S., Stoffel-Wagner, B., Maier, W., \& Hurlemann, R. (2017). Oxytocin facilitates reciprocity in social communication. Social Cognitive and Affective Neuroscience, 12(8), 1325-1333. https://doi.org/10.1093/scan/nsx061

Sripada, C. S., Phan, K. L., Labuschagne, I., Welsh, R., Nathan, P. J., \& Wood, A. G. (2013). Oxytocin enhances resting-state connectivity between amygdala and medial frontal cortex. The International Journal of Neuropsychopharmacology, 16(2), 255-260. https://doi.org/10.1017/S1461145712000533

Stolk, A., Brinkman, L., Vansteensel, M. J., Aarnoutse, E., Leijten, F. S., Dijkerman, C. H., Knight, R. T., de Lange, F. P., \& Toni, I. (2019). Electrocorticographic dissociation of alpha and beta rhythmic activity in the human sensorimotor system. ELife, 8 , e48065. https://doi.org/10.7554/eLife.48065

Stolk, A., D'Imperio, D., di Pellegrino, G., \& Toni, I. (2015). Altered Communicative Decisions following Ventromedial Prefrontal Lesions. Current Biology, 25(11), 1469-1474. https://doi.org/10.1016/j.cub.2015.03.057

Stolk, A., Hunnius, S., Bekkering, H., \& Toni, I. (2013). Early Social Experience Predicts Referential Communicative Adjustments in Five-Year-Old Children. PLOS ONE, 8(8), e72667. https://doi.org/10.1371/journal.pone.0072667

Stolk, A., Todorovic, A., Schoffelen, J.-M., \& Oostenveld, R. (2013). Online and offline tools for head movement compensation in MEG. NeuroImage, 68, 39-48. 
https://doi.org/10.1016/j.neuroimage.2012.11.047

Stolk, A., Verhagen, L., Schoffelen, J.-M., Oostenveld, R., Blokpoel, M., Hagoort, P., van Rooij, I., \& Toni, I. (2013). Neural mechanisms of communicative innovation. Proceedings of the National Academy of Sciences of the United States of America, 110(36), 1457414579. https://doi.org/10.1073/pnas.1303170110

Striepens, N., Matusch, A., Kendrick, K. M., Mihov, Y., Elmenhorst, D., Becker, B., Lang, M., Coenen, H. H., Maier, W., Hurlemann, R., \& Bauer, A. (2014). Oxytocin enhances attractiveness of unfamiliar female faces independent of the dopamine reward system. Psychoneuroendocrinology, 39, 74-87. https://doi.org/10.1016/j.psyneuen.2013.09.026

Thivierge, J.-P., \& Cisek, P. (2008). Nonperiodic Synchronization in Heterogeneous Networks of Spiking Neurons. Journal of Neuroscience, 28(32), 7968-7978. https://doi.org/10.1523/JNEUROSCI.0870-08.2008

Tomasello, M. (2008). Origins of human communication. The MIT Press.

Toni, I., \& Stolk, A. (2019). Conceptual alignment as a Neurocognitive Mechanism for Human Communicative Interactions. In P. Hagoort (Ed.), Human Language: From Genes and Brains to Behavior. (p. 9). MIT Press.

Touboul, J., \& Destexhe, A. (2010). Can Power-Law Scaling and Neuronal Avalanches Arise from Stochastic Dynamics? PLOS ONE, 5(2), e8982. https://doi.org/10.1371/journal.pone.0008982

Tzovara, A., Meyer, S. S., Bonaiuto, J. J., Abivardi, A., Dolan, R. J., Barnes, G. R., \& Bach, D. R. (2019). High-precision magnetoencephalography for reconstructing amygdalar and hippocampal oscillations during prediction of safety and threat. Human Brain Mapping, 40(14), 4114-4129. https://doi.org/10.1002/hbm.24689

Van Overwalle, F. (2011). A dissociation between social mentalizing and general reasoning. NeuroImage, 54(2), 1589-1599. https://doi.org/10.1016/j.neuroimage.2010.09.043

Van Overwalle, F., \& Baetens, K. (2009). Understanding others' actions and goals by mirror and mentalizing systems: A meta-analysis. NeuroImage, 48(3), 564-584. https://doi.org/10.1016/j.neuroimage.2009.06.009

Voytek, B., Kramer, M. A., Case, J., Lepage, K. Q., Tempesta, Z. R., Knight, R. T., \& Gazzaley, A. (2015). Age-Related Changes in $1 / \mathrm{f}$ Neural Electrophysiological Noise. The Journal of Neuroscience, 35(38), 13257-13265. https://doi.org/10.1523/JNEUROSCI.233214.2015

Warren-Leubecker, A., \& Bohannon, J. N. (1984). Intonation patterns in child-directed speech: Mother-father differences. Child Development, 55(4), 1379-1385. https://doi.org/10.2307/1130007

Wen, H., \& Liu, Z. (2016). Separating Fractal and Oscillatory Components in the Power Spectrum of Neurophysiological Signal. Brain Topography, 29(1), 13-26. https://doi.org/10.1007/s10548-015-0448-0

Wu, N., \& Su, Y. (2015). Oxytocin Receptor Gene Relates to Theory of Mind and Prosocial Behavior in Children. Journal of Cognition and Development, 16(2), 302-313. 
https://doi.org/10.1080/15248372.2013.858042

Wu, Y., van Dijk, E., \& Zhou, X. (2013). Evaluating self- vs. other-owned objects: the modulatory role of oxytocin. Biological Psychology, 92(2), 179-184. https://doi.org/10.1016/j.biopsycho.2012.11.011

Wynn, J. K., Green, M. F., Hellemann, G., Reavis, E. A., \& Marder, S. R. (2019). A dose-finding study of oxytocin using neurophysiological measures of social processing. Neuropsychopharmacology: Official Publication of the American College of Neuropsychopharmacology, 44(2), 289-294. https://doi.org/10.1038/s41386-0180165-y

Ye, Z., Stolk, A., Toni, I., \& Hagoort, P. (2017). Oxytocin Modulates Semantic Integration in Speech Comprehension. Journal of Cognitive Neuroscience, 29(2), 267-276. https://doi.org/10.1162/jocn_a_01044

Yoon, S. O., \& Brown-Schmidt, S. (2014). Adjusting conceptual pacts in three-party conversation. Journal of Experimental Psychology. Learning, Memory, and Cognition, 40(4), 919-937. https://doi.org/10.1037/a0036161

Yoon, S. O., \& Brown-Schmidt, S. (2018). Aim Low: Mechanisms of Audience Design in Multiparty Conversation. Discourse Processes, 55(7), 566-592. https://doi.org/10.1080/0163853X.2017.1286225

Zhang, X., Wu, Y. C., \& Holt, L. L. (2021). The Learning Signal in Perceptual Tuning of Speech: Bottom Up Versus Top-Down Information. Cognitive Science, 45(3), e12947. https://doi.org/10.1111/cogs.12947

Zhigalov, A., \& Jensen, O. (2020). Alpha oscillations do not implement gain control in early visual cortex but rather gating in parieto-occipital regions. Human Brain Mapping, 41(18), 5176-5186. https://doi.org/10.1002/hbm.25183

Zhuang, Q., Zhu, S., Yang, X., Zhou, X., Xu, X., Chen, Z., Lan, C., Zhao, W., Becker, B., Yao, S., \& Kendrick, K. M. (2021). Oxytocin-induced facilitation of learning in a probabilistic task is associated with reduced feedback- and error-related negativity potentials. Journal of Psychopharmacology (Oxford, England), 35(1), 40-49. https://doi.org/10.1177/0269881120972347

Zink, C. F., Tong, Y., Chen, Q., Bassett, D. S., Stein, J. L., \& Meyer-Lindenberg, A. (2008). Know your place: neural processing of social hierarchy in humans. Neuron, 58(2), 273-283. https://doi.org/10.1016/j.neuron.2008.01.025 


\section{Supplementary 1: Recruitment and data quality control}

3 The recruitment rate prevented us from completing the full planned sample (40 in each

4 group) given the time and resources available for data collection of this study (Figure S1.).

5 Eighty-nine participants in total were assessed for eligibility, 31 out of them were excluded

6 in the enrolment phase for not meeting the inclusion criteria or no suitable time slots for

7 testing. All the participants matched the following criteria: 1) aged between 18 and 35; 2) right-handed; and had 3) no metal in the body; 4) no claustrophobia; 5) no psychiatric, endocrine, or neurological disorders; 6) no use of medicine (except for normal use of paracetamol), experience in other pharmacological studies or blood donation within the last two months; 7) no use of drugs, alcohol or more than five cigarettes per day; and 8) no working at night ( $>3$ days per month) or intercontinental flights. During analysis phase, three participants were excluded in the behavioral analysis (one participant did not seem to understand the instructions of the task; one participant did not believe our manipulation indexing communicative adjustment, one participant data acquisition failed.) (de Boer et al., 2017). Four other participants were excluded in the current report due to lack of neuroimaging data (Two participants had no MRI recording, one participant had no MEG recording and one participant had no head-location recording). 24 participants in the oxytocin group and 27 participants in the placebo group remained in the final analysis. 


\section{Enrollment}

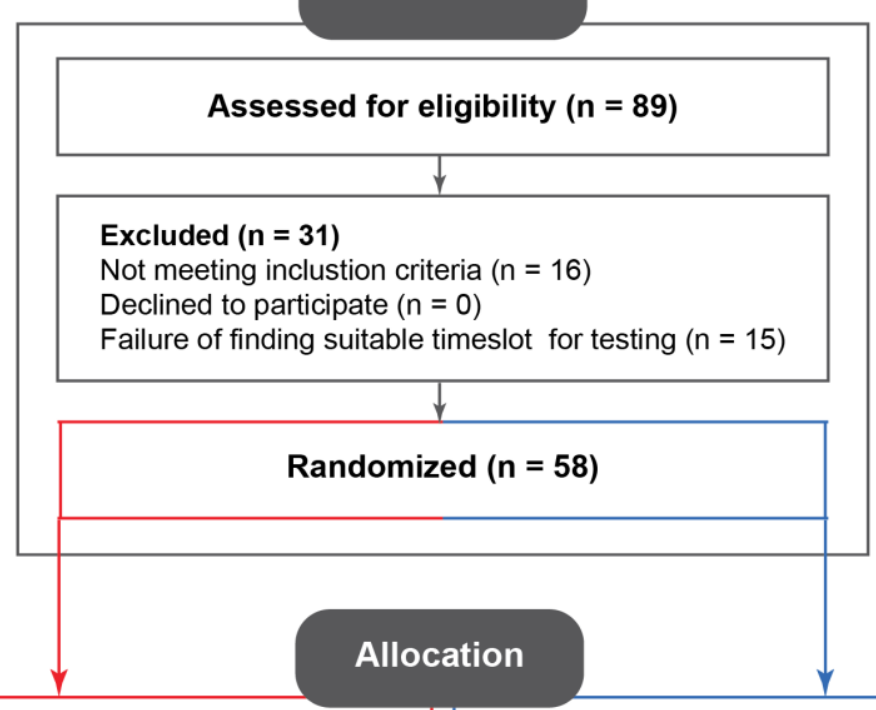

Allocated to intervention Oxytocin $(\mathbf{n}=\mathbf{2 9})$

Recieved allocated intercention $(n=29)$

Did not recieved allocated intervention $(n=0)$

Allocated to intervention Placebo $(n=29)$

Recieved allocated intercention $(n=29)$

Did not recieved allocated intervention $(n=0)$

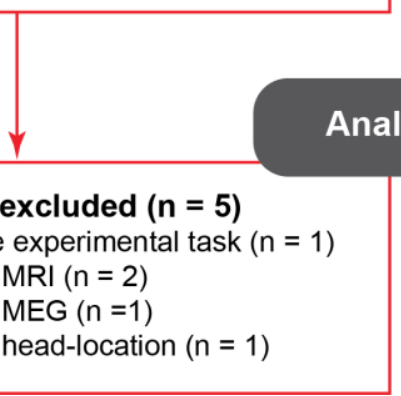

Figure S1. Consort flow diagram. 


\section{Supplementary 2: Control analyses on behavioral, physiological, and}

2 psychological confounding factors

4 Homogeneity between oxytocin and placebo groups with respect to the levels of steroid

hormones, social traits, and beliefs about the psychopharmacological manipulation.

First, to measure cortisol and testosterone levels, we collected salivary samples for three times (i.e. before, 15 minutes after, and 100 minutes after pharmacological administration, with salicaps, Immuno-Biological Laboratories GmbH, Hamburg, Germany). We considered the concentration for each hormone averaged the three time points. Specifically, the samples were stored at $-25^{\circ}$ and analyzed in duplicate for both cortisol and testosterone. Hormone concentration was measured using luminescence Immunoassays (Immuno-Biological Laboratories GmbH, Hamburg, Germany). The intra-assay and inter-assay coefficients of variation were less than $4 \%$ for cortisol, and $0-2 \%$ and 5-9\% for testosterone respectively. Second, immediately after the pharmacological administration, we gave participants a list of self-report questionnaires for measuring empathy (Empathy Quotient; Baron-Cohen \& Wheelwright, 2004; Interpersonal Reactivity Index; Davis, 1983), systemizing abilities (Revised Systemizing Quotient; Baron-Cohen et al., 2003), social anxiety (Liebowitz Social Anxiety Scale; Liebowitz, 1987) and need for cognition traits (Need for Cognition Scale; Cacioppo et al., 1984). Third, after completing the TCG task, the participants also rated on a 7-points Likert scale on their beliefs on the substance and dosage of the pharmacological 
treatment they had received. The oxytocin and placebo groups revealed no statistical

2 difference in the array of independent-sampled t tests (Table S1). These results verified the

3 between-group homogeneity in the levels of steroid hormones, social traits, and beliefs about

4 the psychopharmacological manipulation.

5 Table S1. The oxytocin and placebo groups were matched in social traits, hormone 6 concentration, and beliefs about the psychopharmacological manipulation.

\begin{tabular}{|c|c|c|c|c|c|}
\hline \multirow{2}{*}{ Indexes } & \multicolumn{2}{|c|}{ mean \pm SD } & \multirow{2}{*}{ df } & \multirow{2}{*}{$\mathbf{t}$} & \multirow{2}{*}{$\mathbf{p}$} \\
\hline & Oxytocin & Placebo & & & \\
\hline Empathy Quotient & $33.52 \pm 11.59$ & $36.93 \pm 12.47$ & 49 & -1.000 & .322 \\
\hline Systemizing Quotient & $56.83 \pm 14.37$ & $51.82 \pm 14.81$ & 49 & 1.225 & .226 \\
\hline Need for Cognition Scale & $8.583 \pm 9.036$ & $10.78 \pm 8.05$ & 49 & -.917 & .363 \\
\hline Liebowitz Social Anxiety Scale & $30.50 \pm 16.76$ & $28.56 \pm 19.10$ & 49 & .384 & .703 \\
\hline \multicolumn{6}{|l|}{ Interpersonal Reactivity Index: } \\
\hline Fantasy subscale & $16.96 \pm 4.39$ & $16.52 \pm 4.19$ & 49 & .366 & .716 \\
\hline Empathic concern & $15.08 \pm 4.31$ & $15.63 \pm 3.41$ & & -.504 & 616 \\
\hline Perspective taking & $15.75 \pm 3.53$ & $17.04 \pm 4.87$ & 49 & -1.068 & .291 \\
\hline Personal distress & $11.21 \pm 5.03$ & $10.19 \pm 3.25$ & 49 & .873 & .387 \\
\hline Cortisol (nmol/l) & $8.44 \pm 3.74$ & $9.11 \pm 4.25$ & 49 & -.594 & .555 \\
\hline Testosterone (pg/nl) & $79.25 \pm 42.48$ & $97.32 \pm 87.31$ & 49 & -.921 & .362 \\
\hline $\begin{array}{l}\text { Belief on the type of administration } \\
(-3=\text { placebo, } 0=\text { not sure, } 3=\text { drug })\end{array}$ & $-.13 \pm 1.80$ & $-.18 \pm 1.41$ & 49 & .093 & .927 \\
\hline $\begin{array}{r}\text { Belief on the dosage of administration } \\
(-3=\text { low, } 0=\text { not sure, } 3=\text { high })\end{array}$ & $-.75 \pm 1.60$ & $-.67 \pm 1.47$ & 49 & -.194 & .847 \\
\hline
\end{tabular}
experimental conditions. 
1 influence on the total moving time, time on non-target-field and the number of movement

2 steps made by the participants (Table S2). The results indicated that participants specifically

3 adjusted their communicative behavior but not instrumental responding patterns.

4 We verified that the role-blind confederate provided comparable reaction times and joint

5 correctness of performance in the Adult and Child conditions for the oxytocin and placebo

6 groups, also by conducting mixed-factorial ANOVAs (Table S2). Moreover, we also tested

7 whether the confederate's reaction time and joint error rate predicted Communicative

8 Adjustment (CA). Specifically, we compared the null model with Treatment (i.e. model_0: CA

$9 \sim$ Treatment) with two alternative models: 1) Treatment, confederate's Reaction Time, and

10 their interaction (i.e. model_1: CA $\sim$ Treatment * Reaction Time), and 2) Treatment, Correct

11 rate, and their interaction (i.e. model_2: CA Treatment * Error). The results revealed that

12 adding the extra predictor to Treatment did not help explaining residual variance in CA

13 (model_0 vs. model_1: $\mathrm{F}_{2}=.31, \mathrm{p}=.73$; model_0 vs. model_2: $\mathrm{F}_{2}=1.44, \mathrm{p}=.25$ ). Together,

14 these results suggested that the confederate's response were matched across experimental

15 conditions and unlikely to account for CA effects.

Table S2. Confederate's response was matched across conditions and indexes of task performance other than Communicative Adjustment were unaffected by experimental manipulation.

\begin{tabular}{rrrrc}
\hline Indexes & Effects & df & F & p \\
\hline Moving Time & Addressee & $1 / 49$ & .990 & .325 \\
& Treatment & $1 / 49$ & .058 & .811 \\
& Addressee*Treatment & $1 / 49$ & .211 & .648 \\
Time on & Addressee & $1 / 49$ & 1.545 & .220
\end{tabular}




\begin{tabular}{rrrrr}
\hline Nontarget-Field & Treatment & $1 / 49$ & 3.335 & .074 \\
& Addressee*Treatment & $1 / 49$ & .106 & .746 \\
\hline $\begin{array}{r}\text { Number of } \\
\text { movement steps }\end{array}$ & Addressee & $1 / 49$ & .286 & .597 \\
& Treatment & $1 / 49$ & .059 & .809 \\
Reaction time of & Addressee*Treatment & $1 / 49$ & 1.160 & .287 \\
confederate & Addressee & $1 / 49$ & .385 & .538 \\
& Treatment & $1 / 49$ & $<.001$ & .978 \\
& Addressee*Treatment & $1 / 49$ & 1.297 & .260 \\
\hline Error rate & Addressee & $1 / 49$ & .221 & .641 \\
& Treatment & $1 / 49$ & 1.939 & .170 \\
& Addressee*Treatment & $1 / 49$ & .221 & .641 \\
\hline
\end{tabular}

1

2 We gave participants a questionnaire on the characteristics of the presumed addressees right

3 after the TCG task. We performed mixed-factorial ANOVAs on the continuous dependent

4 variables (Table S3-A), contingent-table tests on the categorical measures without involving

5 the within-subject factor (Table S3-B), and mixed-effect binomial logit regressions on the

6 categorical measures involving both between-subject factor (Treatment: Oxytocin or Placebo)

7 and within-subject factor (Addressee: Child and Adult) (Table S3-C). The mixed-effect

8 binomial logit models included Treatment, Addressee and their interaction as fixed effects,

9 coupled with the random intercept of Participant, the random slope of Transitions and their

10 interaction for the maximal random structure (eq. S1). The p-values were computed by F test

11 with Satterthwaite approximation for denominator degrees of freedom for unbalanced data.

12 The model was fitted with the GLMM module IBM SPSS Statistics 25.0. In sum, no matter

13 what treatment they took, participants of both groups estimated that the adult presumed

14 addressee were much older (mean $\pm \mathrm{SD}=29.57 \pm 5.95$ ) than the child presumed addressee 
1 (mean $\pm \mathrm{SD}=8.32 \pm 2.07$ ); thought that the former was more alike to themselves; and

2 assigned more intellectual attributes to the adult presumed addressee as well. These results

3 further verified that the two addressee conditions differed only in terms of the

4 communicator's expectations about cognitive abilities of the partners to interpret the

5 communicative signals.

$$
D V \sim \text { Treatment } * \text { Addressee }+(1+\text { Addressee } \mid \text { Participant })
$$

7 Table S3. Oxytocin administration did not bias participants' beliefs about ones' own 8 responses, nor their evaluation about attributes of the presumed addresses.

9 A)

\begin{tabular}{rrrrrr}
\hline Indexes & Effects & df & $\mathbf{F}$ & \multicolumn{1}{c}{$\mathbf{p}$} & $\boldsymbol{\omega}^{2}$ \\
\hline How old do you think & Addressee & $1 / 49$ & 684.339 & $<.001^{* * *}$ & .851 \\
your partner is? & Treatment & $1 / 49$ & .463 & .500 & \\
& Addressee*Treatment & $1 / 49$ & .240 & .627 & \\
How alike to you do you & Addressee & $1 / 49$ & 8.985 & $.004^{* *}$ & .069 \\
think your partner is? & Treatment & $1 / 49$ & 2.167 & .147 & \\
& Addressee*Treatment & $1 / 49$ & 3.449 & .069 & \\
\hline
\end{tabular}

10

B)

\begin{tabular}{cccc}
\hline Indexes & df & $\chi^{2}$ (corrected) & p \\
\hline Did you play differently for one of the partners? & 2 & .184 & .912 \\
Who do you think played better? & 1 & $<.0001$ & 1.000 \\
\hline
\end{tabular}

11 C)

\begin{tabular}{crcccc}
\hline Indexes & Effects & df & F & p & Odds ratio \\
\hline Used a computer before? & Addressee & $1 / 98$ & .001 & .975 & \\
& Treatment & $1 / 98$ & .001 & .975 & \\
& Addressee*Treatment & $1 / 98$ & .356 & .552 &
\end{tabular}




\begin{tabular}{|c|c|c|c|c|c|}
\hline \multirow{3}{*}{ Rides a bike? } & Addressee & $1 / 98$ & .066 & .798 & \\
\hline & Treatment & $1 / 98$ & .839 & .362 & \\
\hline & Addressee*Treatment & $1 / 98$ & .066 & .798 & \\
\hline \multirow[t]{3}{*}{ Counts to $100 ?$} & Addressee & $1 / 98$ & 1.303 & .257 & \\
\hline & Treatment & $1 / 98$ & .003 & .958 & \\
\hline & Addressee*Treatment & $1 / 98$ & .003 & .958 & \\
\hline \multirow[t]{3}{*}{ Can do multiplication problems? } & Addressee & $1 / 98$ & 10.918 & $.001^{* *}$ & 42.217 \\
\hline & Treatment & $1 / 98$ & .752 & .388 & \\
\hline & Addressee*Treatment & $1 / 98$ & .752 & .388 & \\
\hline \multirow[t]{3}{*}{ Knows the rules for driving a car? } & Addressee & $1 / 0$ & - & - & Inf \\
\hline & Treatment & $1 / 0$ & - & - & \\
\hline & Addressee*Treatment & $1 / 0$ & - & - & \\
\hline \multirow[t]{3}{*}{ Owns stuffed toys/animals? } & Addressee & $1 / 98$ & 28.426 & $<.001^{* * *}$ & .010 \\
\hline & Treatment & $1 / 98$ & .196 & .659 & \\
\hline & Addressee*Treatment & $1 / 98$ & .145 & .704 & \\
\hline \multirow[t]{3}{*}{ Plays video games? } & Addressee & $1 / 98$ & 10.783 & $.001^{* *}$ & .059 \\
\hline & Treatment & $1 / 98$ & .010 & .919 & \\
\hline & Addressee*Treatment & $1 / 98$ & .010 & .919 & \\
\hline \multirow[t]{3}{*}{ Goes to the store on their own? } & Addressee & $1 / 98$ & 24.139 & $<.001^{* * *}$ & 79.938 \\
\hline & Treatment & $1 / 98$ & $<.001$ & .990 & \\
\hline & Addressee*Treatment & $1 / 98$ & $<.001$ & .990 & \\
\hline \multirow[t]{3}{*}{ Has read the diary of Anne Frank? } & Addressee & $1 / 98$ & 18.651 & $<.001^{* * *}$ & 42.217 \\
\hline & Treatment & $1 / 98$ & .147 & .702 & \\
\hline & Addressee*Treatment & $1 / 98$ & .207 & .650 & \\
\hline \multirow{3}{*}{$\begin{array}{r}\text { Can sing the song "zakdoekje } \\
\text { leggen"? }\end{array}$} & Addressee & $1 / 98$ & .167 & .683 & \\
\hline & Treatment & $1 / 98$ & .165 & .685 & \\
\hline & Addressee*Treatment & $1 / 98$ & 3.020 & .085 & \\
\hline
\end{tabular}




\section{Supplementary 3: MEG data quality}

3 We performed a series of independent-samples t tests on potential MEG confounds. Results

4 are presented in Table S4. First, we verified the homogeneity between oxytocin and placebo

5 groups in averaged head position and variation (movement displacement and rotation along

$6 \mathrm{x}-, \mathrm{y}-$ and $\mathrm{z}$-axes, Figure S2A) in the MEG scanner. Second, we conducted beamforming source

7 reconstruction with balanced epoch lengths between the two treatment groups. Third, we

8 estimated eye-movement induced noise in the MEG signal by considering three dipoles

9 placed on right and left inferior ocular muscles, and another one between the two eyes

10 (Figure S2B). Figure S2C illustrates the spatial distribution of correlations between each of

11 the eye-related dipoles and the MEG sensors. The spatial patterns suggest that the eye-

12 related dipoles captured variance in the MEG signal related to eye-movements. 
A)

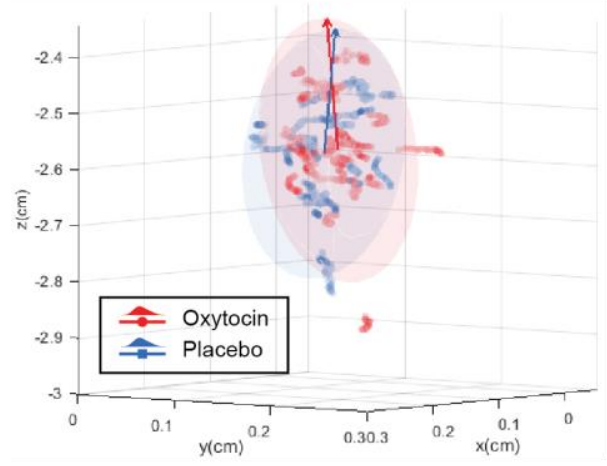

B)

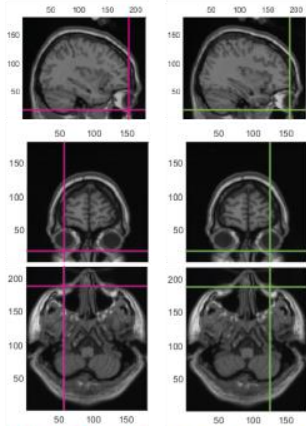

$[-36,61,-56] \quad[36,61,-56]$

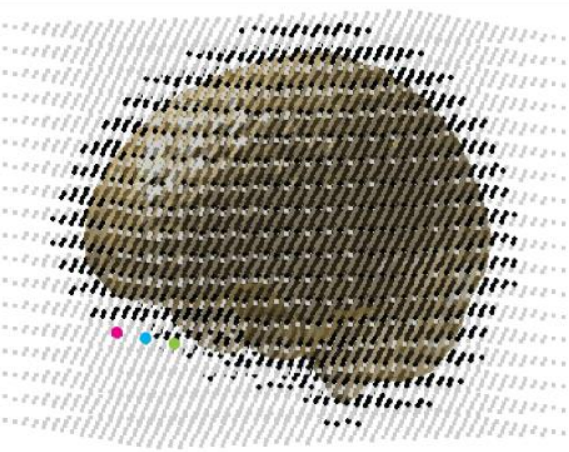

C)

subject 09

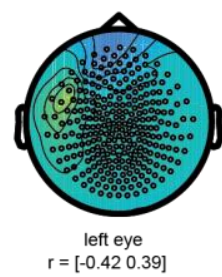

subject 27

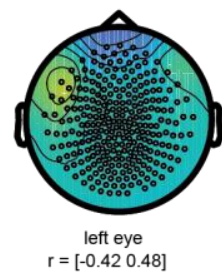

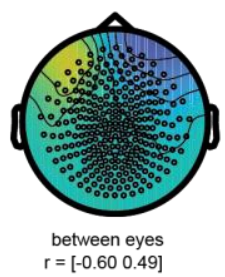

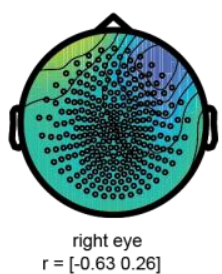

$r=[-0.630 .26]$ subject 30
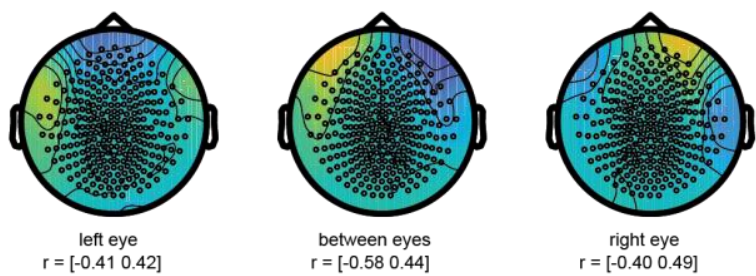

subject 52

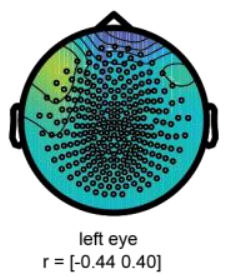

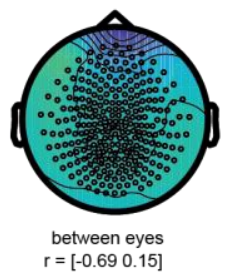

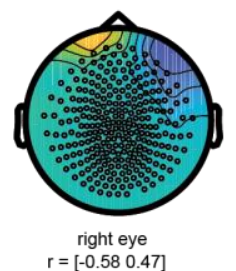

Figure S2. Control analyses of head position and eye-movement noise. A) Trial-by-trial head position of each participant. The red and blue ellipsoids represent average $95 \%$ CI of head position variance of oxytocin and placebo group, respectively. B) The source model that was used for breamforming. We included three dipoles outside the brain, i.e. two on right and left inferior ocular muscles based on the MNI coordinates in the plot and another one in the middle. C) Correlation maps between the estimated source activities of the three dipoles and signals of each MEG sensor. The panels represent correlation maps of four randomly selected participants (two from each treatment group). The $r$ values below each topography indicates the range of correlation coefficients.

Table S4. Control analyses of head position and eye-movement noise.

\begin{tabular}{|c|c|c|c|c|c|}
\hline \multirow{2}{*}{ Indexes } & \multicolumn{2}{|c|}{ mean \pm SD } & \multirow{2}{*}{ df } & \multirow{2}{*}{$\mathbf{t}$} & \multirow{2}{*}{$\mathbf{p}$} \\
\hline & Oxytocin & Placebo & & & \\
\hline
\end{tabular}




\begin{tabular}{rrrrrr}
\hline Average position & $2.58 \pm .09$ & $2.58 \pm .09$ & 49 & .24 & .812 \\
3D variance & $1.5 \mathrm{e}-5 \pm 4.4 \mathrm{e}-5$ & $2.9 \mathrm{e}-6 \pm 5.2 \mathrm{e}-6$ & 49 & -1.37 & .178 \\
Displacement & & & & & \\
$\mathbf{X}$ & $.13 \pm .05$ & $.13 \pm .05$ & 49 & .40 & .693 \\
$\mathbf{Y}$ & $.15 \pm .04$ & $.14 \pm .05$ & 49 & -.85 & .399 \\
$\mathbf{Z}$ & $-2.57 \pm .09$ & $-2.58 \pm .09$ & 49 & -.25 & .802 \\
$\mathbf{X}$ & $93.06 \pm 29.76$ & $95.94 \pm 33.68$ & & .32 & .749 \\
$\mathbf{Y}$ & $100.04 \pm 44.30$ & $81.87 \pm 37.97$ & 49 & -1.58 & .121 \\
$\mathbf{Z}$ & $57.24 \pm 27.13$ & $56.67 \pm 35.50$ & 49 & -.06 & .950 \\
\hline $\begin{array}{r}\text { Rotation } \\
\text { Length of epochs for }\end{array}$ & $3.88 \pm .95$ & $3.85 \pm 1.05$ & 49 & -.12 & .902 \\
computing beamformer & & & & & \\
\hline Estimated eye-movement & $1.7 \mathrm{e}-28 \pm 4.3 \mathrm{e}-29$ & $1.6 \mathrm{e}-28 \pm 5.1 \mathrm{e}-29$ & 49 & -1.12 & .267 \\
\hline
\end{tabular}




\section{Supplementary 4: Correlation between Communicative Adjustment and}

2 Neural Activities in Control Brain Regions

4 We also tested the social saliency hypothesis of oxytocin, by correlating the CA with a

5 biological marker of attentional gating, i.e. inhibition of alpha activity in middle occipital

$6 \operatorname{cortex}\left(\mathrm{t}_{48.29}=1.81, \mathrm{p}=.076\right.$, Estimate(SE) $\left.=.22(.12), 95 \% \mathrm{CI}=[-.02, .46]\right)$. We predicted that

7 oxytocin might increase the alpha power in the visual cortex and/or modulate the neural-

8 behavioral relationship in a way that a lower alpha power might enhance communicative

9 adjustment behavior. However, we did not observe main effect of treatment $\left(t_{410.70}=2.41, p\right.$

$10=.017$, Estimate $(\mathrm{SE})=.23(.10), 95 \% \mathrm{CI}=[.04, .42])$. Moreover, though the model revealed a

11 significant interaction effect between treatment and the alpha activity in middle occipital

12 lobe on CA, the post-hoc test showed no significant correlation between the alpha activity

13 and CA for the oxytocin group ( $\mathrm{t}_{405}=-.91, \mathrm{p}=.36$, Estimate $(\mathrm{SE})=-.06(.06), 95 \% \mathrm{CI}=$

$14[-.18, .07])$. For the placebo group, stronger inhibition of alpha power actually decreased the

15 level of CA $\left(\mathrm{t}_{401}=2.41, \mathrm{p}=.017\right.$, Estimate $\left.(\mathrm{SE})=.17(.07), 95 \% \mathrm{CI}=[.03, .31]\right)$. We reasoned that the communicative adjustment behavior is very likely involving complex feedforward

17 and feedback control processes, so the relationship between visual alpha may not be that straightforward as we postulated. 
A)

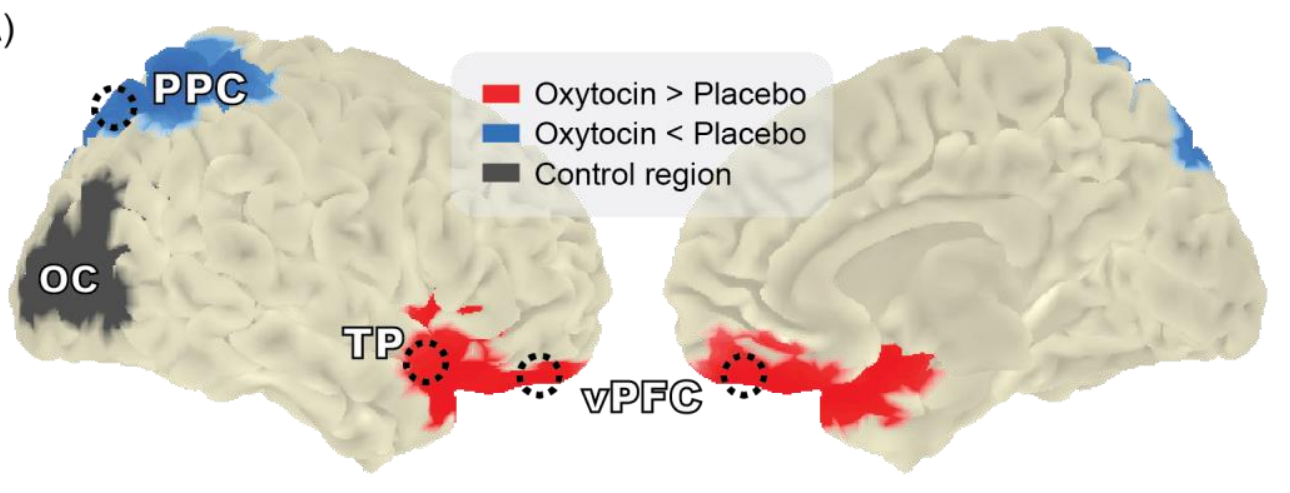

B)
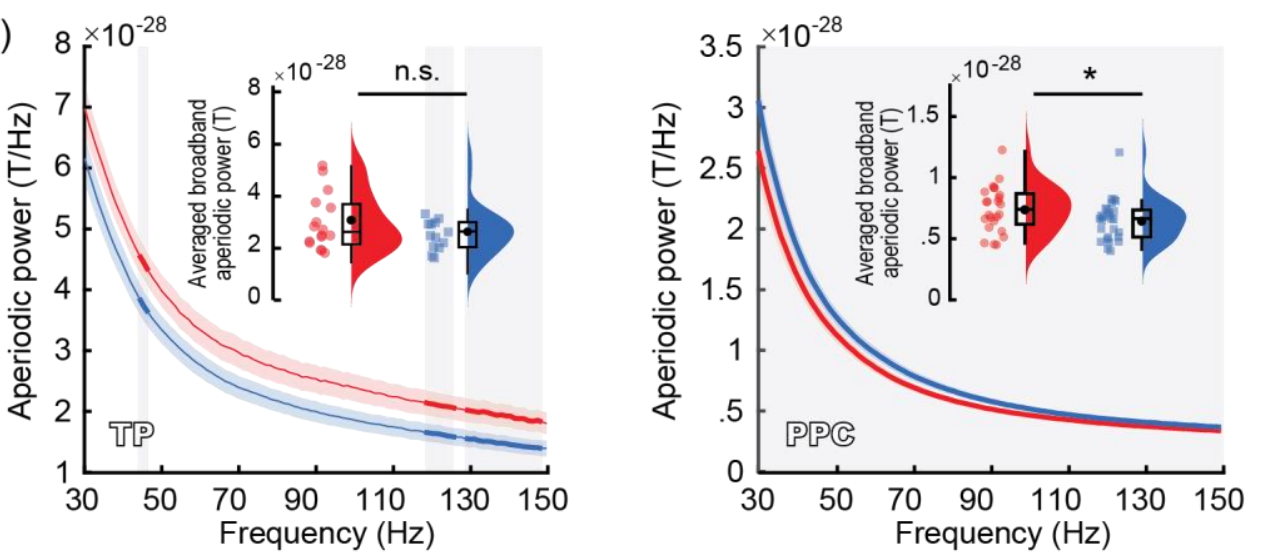

C)
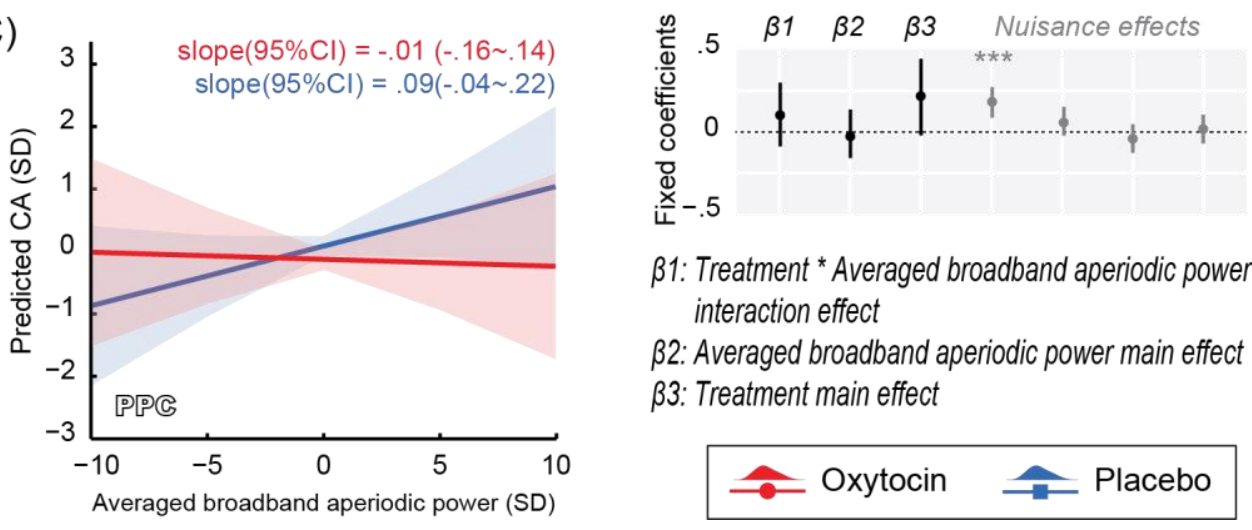

$\beta 1$ : Treatment *Averaged broadband aperiodic power interaction effect

$\beta 2$ : Averaged broadband aperiodic power main effect $\beta 3$ : Treatment main effect

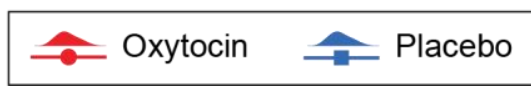

Figure S4. Electrophysiological consequences of oxytocin administration during communicative performance. A) Spatial distribution of oxytocin-related changes in aperiodic broadband power (averaged over 30-150 Hz) with local maxima in right ventral prefrontal cortex (VPFC), temporal pole (TP) and posterior parietal cortex (PPC); and middle

6 occipital lobe as a control region. B) Spectral effects extracted from TP and PPC local maxima

7 (mean \pm SEM, grey area at frequencies and time points where oxytocin and placebo groups

8 are statistically different, $\mathrm{p}<.05$ uncorrected for multiple comparisons over frequencies and

9 time points). Insets show spectrally averaged effects and data distributions, using the same conventions as in Figure 3. C) Oxytocin-related changes in aperiodic broadband power in the 
1 PPC local maximum did not account for inter-participant variation in Communicative

2 Adjustment. The grey panels indicate estimates of the fixed coefficients $\beta 1 \sim 3$ relative to the

3 effects specified in the legend. Error bars: $95 \%$ CI of the mean. ${ }^{* *}$ : $\mathrm{p}<.001{ }^{*}: \mathrm{p}<.05$.

4 Table S5. Fixed effects of neural activity and treatment on Communicative Adjustment 5 (CA).

\begin{tabular}{|c|c|c|c|c|c|c|c|}
\hline Neural property & Effects & Coef & SE & $95 \% \mathrm{CI}$ & $\mathbf{t}$ & df & $\mathbf{p}$ \\
\hline \multirow{3}{*}{$\begin{array}{r}\text { vPFC } \\
\text { (aperiodic broadband) }\end{array}$} & Activity & .15 & .06 & {$[.04, .26]$} & 2.73 & 403.84 & $.007^{* *}$ \\
\hline & Treatment & .22 & .12 & {$[.03, .46]$} & 1.78 & 49.09 & .081 \\
\hline & Activity*Treatment & -.28 & .10 & {$[-.48,-.08]$} & -2.70 & 432.96 & $.007^{* *}$ \\
\hline \multirow{3}{*}{$\begin{array}{r}\text { vPFC } \\
\text { (periodic gamma) }\end{array}$} & Activity & -.01 & .06 & {$[-.13, .11]$} & -.15 & 449.58 & .883 \\
\hline & Treatment & .21 & .12 & {$[-.03, .46]$} & 1.75 & 48.36 & .087 \\
\hline & Activity*Treatment & -.06 & .09 & {$[-.25, .12]$} & -.68 & 445.33 & .497 \\
\hline \multirow{3}{*}{$\begin{array}{r}\text { PPC } \\
\text { (aperiodic broadband) }\end{array}$} & Activity & -.01 & .08 & {$[-.16, .14]$} & -.15 & 282.28 & .885 \\
\hline & Treatment & .21 & .12 & {$[-.03, .46]$} & 1.74 & 48.08 & .088 \\
\hline & Activity*Treatment & .11 & .10 & {$[-.09, .31]$} & 1.05 & 359.08 & .296 \\
\hline \multirow{3}{*}{$\begin{array}{r}\text { PPC } \\
\text { (periodic alpha) }\end{array}$} & Activity & -.00 & .07 & {$[-.13, .13]$} & -.05 & 433.56 & .962 \\
\hline & Treatment & .21 & .12 & {$[-.03, .46]$} & 1.76 & 48.46 & .085 \\
\hline & Activity*Treatment & .06 & .09 & {$[-.12, .25]$} & .68 & 450.15 & .494 \\
\hline \multirow{3}{*}{$\begin{array}{r}\text { PPC } \\
\text { (periodic beta) }\end{array}$} & Activity & -.04 & .07 & {$[-.18, .09]$} & -.62 & 430.95 & .537 \\
\hline & Treatment & .21 & .12 & {$[-.04, .46]$} & 1.70 & 48.38 & .096 \\
\hline & Activity*Treatment & .16 & .10 & {$[-.03, .35]$} & 1.66 & 437.65 & .097 \\
\hline \multirow{3}{*}{$\begin{array}{r}\text { OC } \\
\text { (aperiodic alpha) }\end{array}$} & Activity & -.06 & .06 & {$[-.18, .07]$} & -.91 & 404.52 & .361 \\
\hline & Treatment & .22 & .12 & {$[-.02, .46]$} & 1.81 & 48.29 & .076 \\
\hline & Activity*Treatment & .23 & .10 & {$[.04, .42]$} & 2.41 & 410.70 & $.017^{*}$ \\
\hline \multirow{3}{*}{$\begin{array}{r}\text { OC } \\
\text { (mixed alpha) }\end{array}$} & Activity & -.06 & .06 & {$[-.18, .07]$} & -.92 & 423.80 & .360 \\
\hline & Treatment & .22 & .12 & {$[-.03, .46]$} & 1.80 & 48.30 & .078 \\
\hline & Activity*Treatment & .17 & .10 & {$[-.02, .36]$} & 1.81 & 418.34 & .072 \\
\hline
\end{tabular}


1 Supplementary 5: Changing Rate of Communicative Adjustment and

2 Correlation with Aperiodic Power in vPFC

$4 \quad$ Changing Rate of Communicative Adjustment (CRCA)

5 As the within-subject variance of Communicative Adjustment (CA) differed in the first- vs.

6 the second-half of experiment (Figure S5A showed group averaged and each participant's CA

7 time course), that oxytocin administration might facilitate learning the actual communicative

8 performance of the presumed addressees. A possible consequence of oxytocin-related

9 improved learning is that the oxytocin group became more certain about their

10 communicative adjustment. This should result in greater consistency in CA time courses in

11 the oxytocin than in the placebo group. Here, we tested that hypothesis by quantifying the

12 Changing Rate of Communicative Adjustment (CRCA), computed as the gradient norm of CA(t)

13 with respect to the number of addressee transitions t (eq. S2).

$$
C R C A=\|\nabla C A(t)\| \quad\left(\left\{t \mid t \leq 9, t \in Z^{+}\right\}\right)
$$

15 The norm of the gradient indicates the greatest change of $\mathrm{CA}(\mathrm{t})$ at time point $\mathrm{t}$. A smaller

16 CRCA reflects stabilization of the CA(t) over addressee transitions, i.e. convergence of the

17 CA(t) time course. Therefore, we predicted a steeper descent of CRCA in the oxytocin group

18 than in the placebo group.

19 CRCA allowed us to further probe the question whether oxytocin made communicators more

20 efficient in converging to a certain level of CA, suggesting more certainty in their prediction 
about the addressees' response. We used a linear mixed-effects model to account for within subject variances, with three fixed effects: the pharmacological treatment (Treatment: Oxytocin, Placebo), transitions between addressees (Transition: nine addressee transitions), and the interaction between Treatment and Transition. We included Participant as the grouping variable and considered three random effects: the random intercept of communicators, the random slope of Transitions, and their interaction (eq. S3).

$$
\text { CRCA } \sim \text { Treatment } * \text { Transition }+(1+\text { Transition } \mid \text { Participant })
$$

\section{Oxytocin group showed a faster converged time course of communicative adjustment than the} placebo group.

First, we observed that Transition revealed a significant main effect $\left(t_{49}=-3.95, p<.001\right.$, Estimate(SE) $=-.11(.03), 95 \% \mathrm{CI}=[-.16,-.05])$. Specifically, CRCA descended significantly as a function of Transition in oxytocin (Estimate(SE) $=-.11(.03), 95 \% \mathrm{CI}=[-.16,-.05]$ ) but not in placebo (Estimate(SE) $=-.01(.03), 95 \% \mathrm{CI}=[-.06, .04])$ groups. The results suggested that both groups gained information from the presumed addressees' responses during communication and made use of such information to update their adjustment behavior. Critically, the model revealed a significant interaction effect $\left(\mathrm{t}_{49}=2.67, \mathrm{p}=.01\right.$, Estimate(SE) $=.10(.04), 95 \% \mathrm{CI}=[.02, .18]$, Figure S2B). Consistent with our hypothesis, the oxytocin group showed a faster descent of CRCA over time than the placebo group did ( $\mathrm{t}_{49}=-2.67, \mathrm{p}$ $=.01$, Estimate $(\mathrm{SE})=-.10(.04))$. These results indicated that oxytocin facilitated convergence 
towards a more efficient recipient design and developed a higher confidence in their predictions of addressees' responses during communication. These results together suggested that participant, who took oxytocin intranasal sprays, went through different exploration for the optimal level of CA for the presumed addressees. The more certainty in their prediction, the more likely communicators sustain the current level of CA, thus, smaller CRCA. We expected that oxytocin promoted recipient design by fastening the exploration process, leading to greater reduction of CRCA over time.

The oxytocin-related upregulation of aperiodic broadband power in ventral prefrontal cortex modulates convergence of communicative adjustment

We extracted the random slope per participant from the analysis above, as an index of convergence speed of CA time course, indicating how fast a communicator achieve a stable level of communicative adjustment. Further, we examined the relationship between the magnitude of broadband aperiodic power in vPFC and convergence speed of CA. The results showed a significant main effect of broadband aperiodic power on the random slopes ( $\mathrm{t}_{402.20}$ $=-3.61, \mathrm{p}<.001$, Estimate $(\mathrm{SE})=-.18(.06), 95 \% \mathrm{CI}=[-.28,-.08])$ and an interaction between treatment and broadband aperiodic power on CA $\left(\mathrm{t}_{429.79}=2.50, \mathrm{p}=.013\right.$, Estimate(SE) $=.24(.10), 95 \%$ CI $=[.05, .43]$, Figure S5C). Specifically, the interaction indicates that oxytocin modulated the effect of broadband aperiodic power on the temporal dynamics of communicative adjustment; namely, a larger broadband aperiodic power in vPFC predicted faster convergence of the communicative adjustment time course (i.e. a steeper random 
1 slope) in the oxytocin group ( $\mathrm{t}_{402}=-3.61, \mathrm{p}<.001$, Estimate $(\mathrm{SE})=-.18(.05), 95 \% \mathrm{CI}=[-.28$,

$2 \quad-.08]$ ). However, no significant correlation was observed in the placebo group $\left(\mathrm{t}_{436}=.69, \mathrm{p}\right.$

$3=.494$, Estimate $(\mathrm{SE})=.06(.08), 95 \% \mathrm{CI}=[-.10, .21])$. Moreover, we did not find association

4 between CRCA and neural activities in other brain regions and spectral domains as shown in

5 Table S6. In sum, these results indicate that the oxytocinergic upregulation of aperiodic

6 broadband power in ventral prefrontal cortex promotes a more efficient recipient design

7 during the course of communication, rather than stereotypically increase communicative

8 adjustment based on their initial prediction about the interacting partner. 
A)
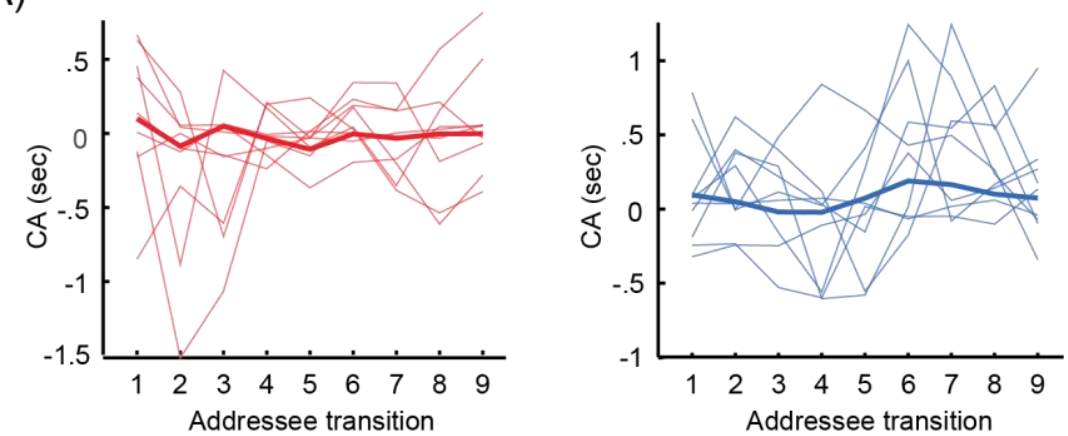

B)
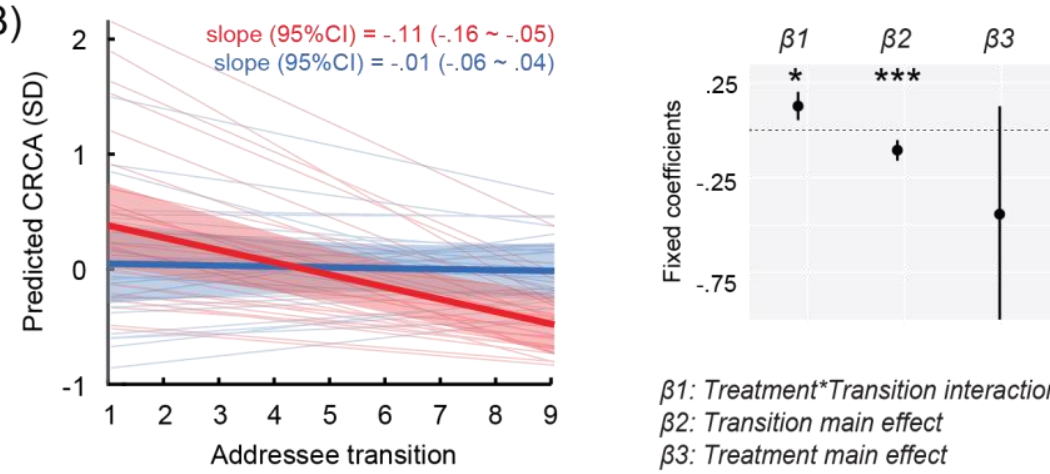

$\beta 1:$ Treatment ${ }^{\star}$ Transition interaction

B2: Transition main effect

B3: Treatment main effect

C)
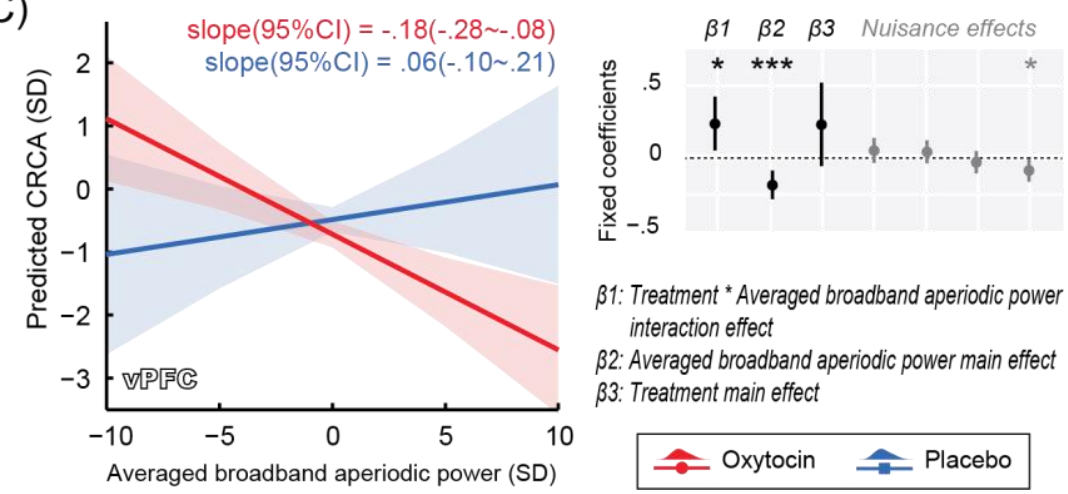

Figure S5. Dynamics of communicative adjustment and its correlation with aperiodic neural activity in vPFC. A) The Communicative Adjustment (CA) dynamics. Each thinner line represents the CA time course per participant who was assigned to oxytocin (in red) or placebo (in blue) treatment group. The thicker lines represent group averaged CA. B) The oxytocin group showed steeper slope of Changing Rate of Communicative Adjustment (CRCA) over time, suggesting a faster stabilization of CA in the oxytocin group than the placebo group. The thinner lines represent predicted CRCA per participant by the mixed-effect model; the thicker lines represent predicted group averages of CRCA. The grey panel indicates the fixed coefficients $\beta 1 \sim 3$ relative to the effects specified in the legend. Error bars: $95 \%$ CI of the predicted mean. C) Oxytocin-related changes in aperiodic broadband power in the vPFC local maximum account for inter-participant variation in CRCA. ${ }^{* * *}: \mathrm{p}<.001{ }^{*}: \mathrm{p}<.05$. 
1 Table S6. Fixed effects of neural activity and treatment on Changing Rate of

2 Communicative Adjustment (CRCA).

\begin{tabular}{|c|c|c|c|c|c|c|c|}
\hline Neural property & Effects & Coef & SE & $95 \% \mathrm{CI}$ & $\mathbf{t}$ & df & $\mathbf{p}$ \\
\hline \multirow{3}{*}{$\begin{array}{r}\text { vPFC } \\
\text { (aperiodic broadband) }\end{array}$} & Activity & -.18 & .05 & {$[-.28,-.08]$} & -3.61 & 402.20 & $<.001^{* * *}$ \\
\hline & Treatment & .23 & .15 & {$[-.07, .53]$} & 1.56 & 48.92 & .125 \\
\hline & Activity*Treatment & .24 & .10 & {$[.05, .43]$} & 2.50 & 429.79 & $.013^{*}$ \\
\hline \multirow{3}{*}{$\begin{array}{r}\text { vPFC } \\
\text { (periodic gamma) }\end{array}$} & Activity & -.06 & .06 & {$[-.18, .05]$} & -1.08 & 431.62 & .281 \\
\hline & Treatment & .21 & .16 & {$[-.10, .53]$} & 1.36 & 48.88 & .180 \\
\hline & Activity*Treatment & .08 & .09 & {$[-.10, .25]$} & .87 & 436.03 & .384 \\
\hline \multirow{3}{*}{$\begin{array}{r}P P C \\
\text { (aperiodic broadband) }\end{array}$} & Activity & -.02 & .07 & {$[-.17, .12]$} & -.34 & 306.82 & .733 \\
\hline & Treatment & .21 & .15 & {$[-.10, .52]$} & 1.37 & 48.60 & .177 \\
\hline & Activity*Treatment & .06 & .10 & {$[-.13, .25]$} & .63 & 417.25 & .530 \\
\hline \multirow{3}{*}{$\begin{array}{r}\text { PPC } \\
\text { (periodic alpha) }\end{array}$} & Activity & .03 & .06 & {$[-.09, .16]$} & .56 & 422.72 & .575 \\
\hline & Treatment & .21 & .15 & {$[-.09, .52]$} & 1.40 & 48.91 & .168 \\
\hline & Activity*Treatment & -.03 & .09 & {$[-.20, .14]$} & -.32 & 431.93 & .750 \\
\hline \multirow{3}{*}{$\begin{array}{r}\text { PPC } \\
\text { (periodic beta) }\end{array}$} & Activity & -.02 & .06 & {$[-.14, .11]$} & -.48 & 431.91 & .812 \\
\hline & Treatment & .21 & .15 & {$[-.10, .52]$} & 1.39 & 48.63 & .172 \\
\hline & Activity*Treatment & -.01 & .09 & {$[-.18, .17]$} & -.07 & 434.63 & .947 \\
\hline \multirow{3}{*}{$\begin{array}{r}\text { OC } \\
\text { (periodic alpha) }\end{array}$} & Activity & .07 & .06 & {$[-.04, .19]$} & 1.25 & 390.09 & .211 \\
\hline & Treatment & .20 & .15 & {$[-.10, .51]$} & 1.34 & 48.53 & .187 \\
\hline & Activity*'Treatment & -.08 & .09 & {$[-.25, .10]$} & -.84 & 397.45 & .401 \\
\hline \multirow{3}{*}{$\begin{array}{r}\text { OC } \\
\text { (mixed alpha) }\end{array}$} & Activity & .06 & .06 & {$[-.06, .17]$} & .96 & 402.18 & .337 \\
\hline & Treatment & .21 & .15 & {$[-.10, .51]$} & 1.36 & 48.55 & .180 \\
\hline & Activity*Treatment & -.03 & 0.09 & {$[-.21, .14]$} & -.38 & 400.59 & .700 \\
\hline
\end{tabular}

